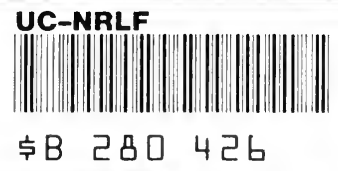



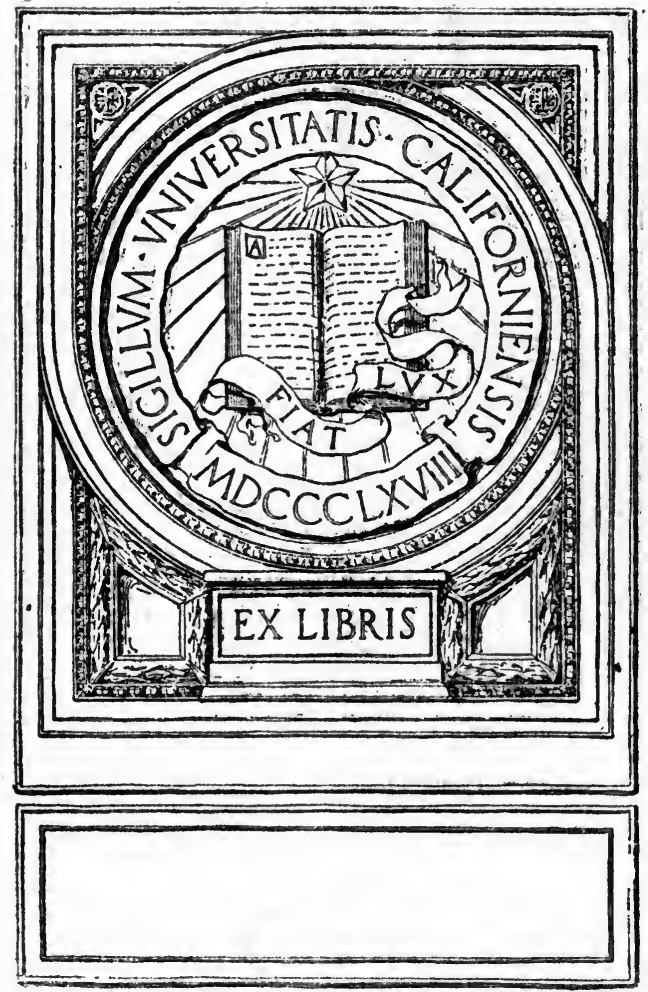
Digitized by the Internet Archive in 2007 with funding from

Microsoft Corporation 


\section{THE HUMAN MACHINE AND}

INDUSTRIAL EFFICIENCY 


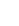




\section{THE HUMAN MACHINE}

aND

\section{INDUSTRIAL EFFICIENCY}

BY

\section{FREDERIC S. LEE, Ph.D., LL.D.}

Dalton Professor of Physiology in Columbia University; President of the American Physiological Society; Consulting Physiologist to the $U$. S.

Public Health Service; Chairman of the Sub-Committee on Fatigue in Industrial Pursuits of the National Research Council; Executive Secretary of the Divisional

Committee on Industrial Fatigue under the Advisory Commission of the Council of National Defense

WITH,LLUSTRATIONS

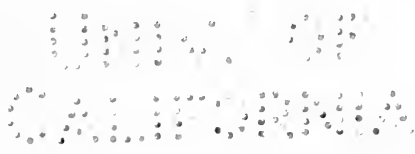

L O N G M A N S, G R E E־ A N D C O. FOURTH AVENUE \& 30Tн STREET, NEW YORK

39 PATERNOSTER ROW, LONDON BOMBAY, CALCUTTA, AND MADRAS

1918 


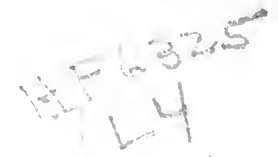

Copyright, 1918

BY FREDERIC S. LEE

All Rights Reserved 


\section{PREFACE}

Most of the substance of this little book constituted the two Cutter Lectures on Preventive Medicine and Hygiene, which were given at the Harvard Medical School, April 25 and 26, 1918, under the title "Industrial Efficiency and the War." Many of the facts here presented relate to war industries, but they are none the less pertinent as illustrating the principles enunciated; and even if interest in the facts dies out, the principles, it is hoped, will survive and receive attention long after the war has ended. I believe fully that any activity in which the human body plays so large a part as it does in industry must be organized on a physiological basis before the highest degree of efficiency can be secured. In the field of human activity here discussed a science of industrial physiology must come into being, a science of the human machine in industry, and this must be developed largely within industrial establishments themselves. They constitute the laboratories in which much of the observation and experiment of the future must be made. If I can help to make this thought accepted by others than 


\section{PREFACE}

physiologists and especially by industrial leaders, I shall be gratified.

In preparing this summary of our present knowledge I am under many obligations to my colleagues in the U. S. Public Health Service and the Committees on Industrial Fatigue. Their names will be found at the beginning of the Bibliography printed at the end of the volume. The numbers in the text refer to the Bibliography.

Frederic S. Lee.

Columbia University,

June 1, 1918. 


\section{CONTENTS}

I. INTRODUCtion •

II. The Qualifications of Workers . • . 5

III. Output and Fatigue

IV. Secondary Sources of Fatigue $\quad$. $\quad$. $\quad$. 19

V. Resting Periods . . . . . . . . . 24

VI. The Length of the Working Day . . . 29

VII. Capacity and the Self-limitation of Output 39

VIII. The Maintenance of Working Power. Over-

TIME . . . . . . . . . . . 43

IX. The Labor Turnover . . . . . . . 49

X. The Industrial Efficiency of Women ComPAREd With MeN . . . . . . 53

XI. Night Work in Comparison with Day Work 61 XII. Industrial Accidents . . . . . . . 73

XIII. Industrial Medicine. Welfare Work . . 79 -

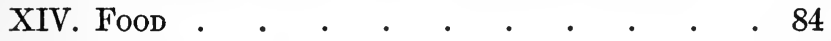
XV. Scientific Management . . . . . 90

XVI. The Physiological Organization of Work . 96

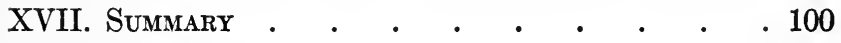
BIBLIOGRAPHY • . . . . . . . 105 INDEX . . . . . . . . . . 


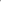




\section{THE HUMAN MACHINE}

\section{I \\ INTRODUCTION}

In the modern factory the science of machinery is developed to its highest point. In the selection, construction, and use of the machine nothing is left to chance. Its type is selected in accordance with its exact fitness for the work demanded of it. It is constructed of appropriate materials and is so designed as to avoid lost motion and the waste of energy involved and to allow the highest possible proportion of the total energy that is transformed to perform the work required. It is kept clean, unnecessary friction is avoided, and every care is taken that its bearings shall not become corroded, rusted, or worn beyond repair. When in action it is run at a specd for which it is planned, it is not overloaded, and not overheated; the conditions under which it can work with the greatest efficiency have been carefully studied; and every effort is made to maintain these conditions and secure the largest possible output with- 
out injury or unnecessary deterioration of the machine itself. And the machine, it should be added, responds to all the care expended on its welfare and proves by what it does the value of the efforts made in its behalf.

But there is another element in factory equipment which must direct, make useful and supplement the machinery, and this is the human element. The term "labor-saving machinery" is misleading; for, while the modern factory machine does indeed save labor in some degree, it gives labor more opportunities, directs it into new channels, confines it to more specialized operations, and makes it more necessary than ever to industrial advance. It is pertinent to our present purpose to regard this human element, the combined body and mind of the worker, as itself a machine. There is nothing derogatory to the worker in this conception; it is the customary conception of physiological science, which has learned to respect living substance above all other created things and yet finds it most helpful to regard every living body as a mechanism working according to the fundamental laws of all mechanisms, but with its own specific ways of acting that characterize living in contrast to non-living substance. No other factory mechanism approaches this human machine in its intricacy, the perfection of the correlation of its working parts, its combination of delicacy 
and strength, and its adaptability to the work required of it. None is so essential to industry.

Nevertheless, the present ways of handling the human machine are empirical and crude. Experience has taught most industrial managers what they believe to be the proper ways of dealing with the workers, and experience is conceived to be the best guide. The thought that the worker is a physiological mechanism and should be treated as such, that the problem of the worker is a physiological problem, is regarded as academic, fit for the laboratory, but not "practical" enough for the factory. That word "practical" is one of the most alluring, most dangerous and most misused words in the English tongue. Crimes unnumbered have been committed in its name. It is true that the science of the human machine as employed in industrial work has not yet been developed so far as that of non-living machinery, but the utilization of the science has not kept pace with its advance, and though here and there a factory management stands out as being fully alive to the desirability of organizing its work on a really scientific basis, to the average manager this is yet to be proved.

The war is making unprecedented demands on industry. It is now generally recognized that toward the winning of the war industrial effort must contribute as much as military effort, and 
just as military activity is everywhere seeking as never before the aid of science, so the industrial system, if it would respond loyally to the call upon it, cannot continue to rely upon its traditional methods, but should utilize whatever help science can give. That physiology can give much to industry has been demonstrated during the past three years by investigations that have been carried on, in both America (1) and England (2), especially in munition factories, and it is chiefly to some of the results of these investigations that the present pages are to be devoted.

In order that the highest degree of efficiency may be secured in industrial work, it would seem obvious that certain fundamental conditions should be fulfilled. These include the following:

1. Workers should be qualified for the work that they are to do.

2. Workers should produce a daily output in accordance with their individual capacities for work.

3. Workers should maintain their working power from day to day and from week to week.

4. Workers, once they are proved competent, should be retained.

These conditions seem axiomatic, and yet they are rarely fulfilled. In the following pages I propose to consider them, as well as certain other topics relating to the human machine in industry. 


\section{II}

THE QUALIFICATIONS OF WORKERS

MODERN industry makes an infinite variety of demands on the physical and mental qualifications of its workers. The number of different operations that are required in any branch of a single manufacture are little known to the layman. The simple assembling of the various parts of the engine of an automobile consists of some two hundred distinct manipulations, and with the modern division of labor these can most advantageously be assigned to at least an equal number of operatives. Before the assembling come the thousands of tasks involved in the manufacture of the different parts. It is reported of one large factory that in the process of manufacturing its goods more than a half million different acts must be performed. Wherever these varied acts are performed by machinery the use of machines not properly adapted to the work would obviously be inexcusable. The time and thought that are given to the invention and perfection of machines and the determination of the ways 
by which they can be handled most efficiently are a measure of the demands for mechanical fitness that are made by the industrial manager.

To the qualifications of the human machine, however, the manager usually gives little preliminary attention. The custom frequently is to hire with but little previous examination whoever applies for a position, assign him to a particular task, and learn then what he is capable of - a method that imposes upon the quantity and quality of the manufactured product the possibility of his failure. The cost of this failure manifested in misused time and spoiled work would be saved if the worker, before being given valuable raw material, would be made to prove his qualifications by proper tests.

From various directions, especially from the psychological laboratories, come suggestions of methods for determining special vocational fitness. The work of Münsterberg (3) is well known, in which he describes simple tests for memory, attention; intelligence, exactitude and rapidity in the case of telephone operators, and attention tests with motormen in street railway service. It must be confessed, however, that the whole matter of ascertaining occupational aptitudes is still in its infancy, and the laboratories and factories are still far removed from really adequate methods. 
There are here needed both analyses of the tasks for the purpose of learning what human qualifications they require, and adequate tests to determine whether individuals possess the required qualifications. Hollingworth (4), in a recent survey of the topic of vocational psychology, while recognizing that " there are some twenty types of work for which tests have already been proposed, recommended, and more or less tentatively tried," concludes that "the reliable vocational psychograph, which proceeds by means of a careful preliminary analysis of the qualities required in the given work, and uses specially adapted tests with reliable norms for their evaluation, is not yet available for any single occupation. The preliminary analyses, so far made, whether by employer, psychologist, or engineer, give us little guidance, and until such guidance is forthcoming the special adaptation of tests and the accumulation of norms and standards cannot make much practical progress." Here is needed above all else the aid of the laboratories, both within and without industrial establishments, and in performing the task the two sciences of physiology and psychology must work hand in hand.

But notwithstanding the present lack, the war has brought into prominence certain methods that promise to be valuable. The general intelligence 
tests which our army has adopted are affording data for the mental classification of our soldiers. Our aviation service, by means of carefully planned and conducted physiological and psychological experiments, is determining standards by means of which the capabilities of our aviators at different altitudes and for different varieties of service will become known. Lovett and Martin's (5) springbalance muscle test, originally designed for the determination of the degree of recovery in muscles paralyzed in poliomyelitis, has, during the past ten months, been used with excellent results in our munition factories. This consists in measuring, by a very simple and quickly applied method, the strength of certain selected groups of muscles and computing from the figures thus obtained the total strength of the individual. Individuals are then classified into four groups: the exceptionally strong, the strong, the moderately strong, and the weak. The use of this test by Professor Martin under the Public Health Service (1) has disclosed the fact that different specific industrial operations have different specific standards of strength, as is illustrated by the following table:

Operation

Average Strength MEN in Pounds

Rivet dipping. . ............... 4870 Rivet trucking................ 4830 


\section{QUALIFICATIONS OF WORKERS 9}

OpERATION

MEN

Average

Strength

IN Pounda

Hot forging. . . . . . . . . . . . . . 4370

Rivet shoveling. . . . . . . . . . . . . 4260

Coal passing. ................... 4230

Capstan lathe (day shift)............ 4180

Planish seat. . . . . . . . . . . . . . 3930

Foremen . . . . . . . . . . . . . . . . . 3770

Powder loading. ............... 3700 WoMEN

Drilling flash holes.............. 2370

Mill percussion flash.............. 1780

Welsbach foot press............... 1640

Drilling diagonal holes............. 1630

It is obvious that if the strength of any worker consistently falls much below the standard for the task to which he has been assigned, he is undertaking work for which he is not physically fitted; and if his strength is markedly greater than that of his task he is not economically placed. These disadvantages in assigning the worker to the task that is unsuited to his strength could be avoided if the spring-balance test should come into general industrial use. 


\section{III}

\section{OUTPUT AND FATIGUE}

A CAREFul study of the hourly and daily output of individual workers in specific tasks throws much light ùpon the general problem of the human machine in industry and its efficiency (6). Such a study is being made in some of our munition factories by the U. S. Public Health Service working in cooperation with the Committees on Industrial Fatigue under the National Research Council and the Advisory Commission of the Council of National Defense (1).

The manufacture of fuses for explosive shells offers excellent opportunities for the study. In the making of a single fuse several hundred separate operations are required, and these are usually assigned to at least as many different workers. The work is repetitive; each operation is comparatively brief and simple and is repeated successively throughout the whole working period as the constant train of similar parts passes before the worker, who may thus perform his task several thousand times between morning and night. In 
most of the operations a non-living and a human machine combine. An automatic recorder or an observer may record the number of times the operation is performed, or the number of pieces completed may either be counted or be calculated from the weight of the product. A convenient unit of time for the measurements is one hour. It is thus easy to obtain the curve of output throughout the working period.

This curve is found to vary with the character of the work. Of operations that require careful attention and exact muscular coordination, that of applying lacquer to certain screw-holes of the fuse is typical. Such a curve showing the hourly distribution of the work of women during a tenhour period of the day shift, is reproduced in Fig. 1. The work began at 7 o'clock in the morning and continued until 12 o'clock noon; there was then a break of one hour for luncheon and recreation; the afternoon work began at 1 and ended at 6 o'clock. The average number of pieces handled by each person during the day was 6250 , of which 3250 were finished in the forenoon and 3000 in the afternoon. The output, which began well, increased during the first two hours of the forenoon spell and by 9 o'clock had reached a maximum 11 per cent above the product of the first hour; it then decreased at almost a constant rate through- 
out the remainder of the spell and by noon had fallen 6 per cent below the record for the first hour and 17 per cent below the maximum. The curve

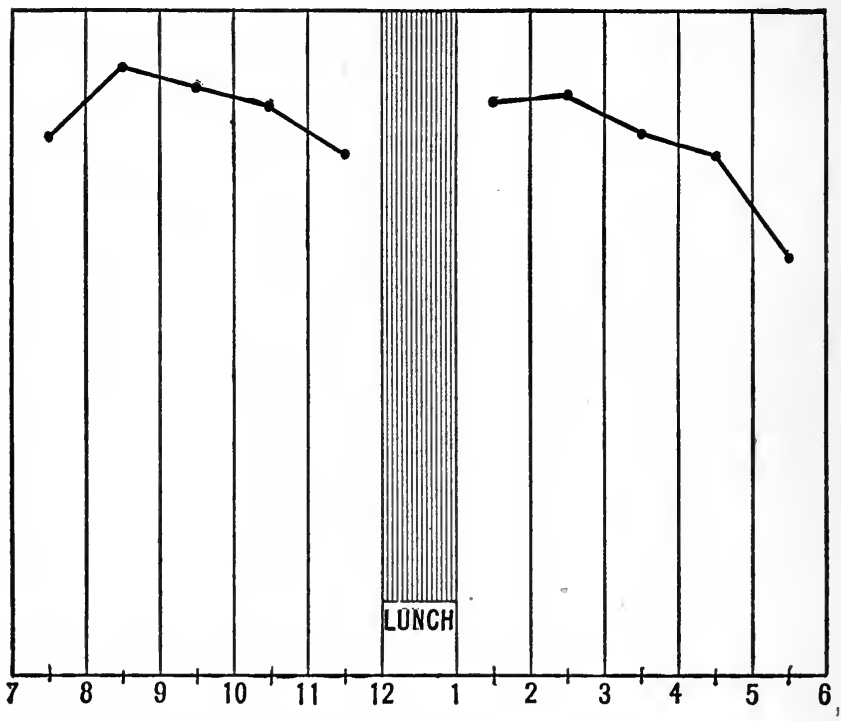

Frg. 1.-Curve of output in painting screw-holes with lacquer, an industrial operation that requires careful attention and exact muscular coordination. The height of each point in the curve above the base line represents the output of the corresponding hour. Women workers; day work; 10hour shift. (By courtesy of the U. S. Public Health Service.)

of the afternoon spell shows a general form similar to that of the morning but with quantitative differences; the first hour's production is greater than 


\section{,}

$$
\text { - }
$$




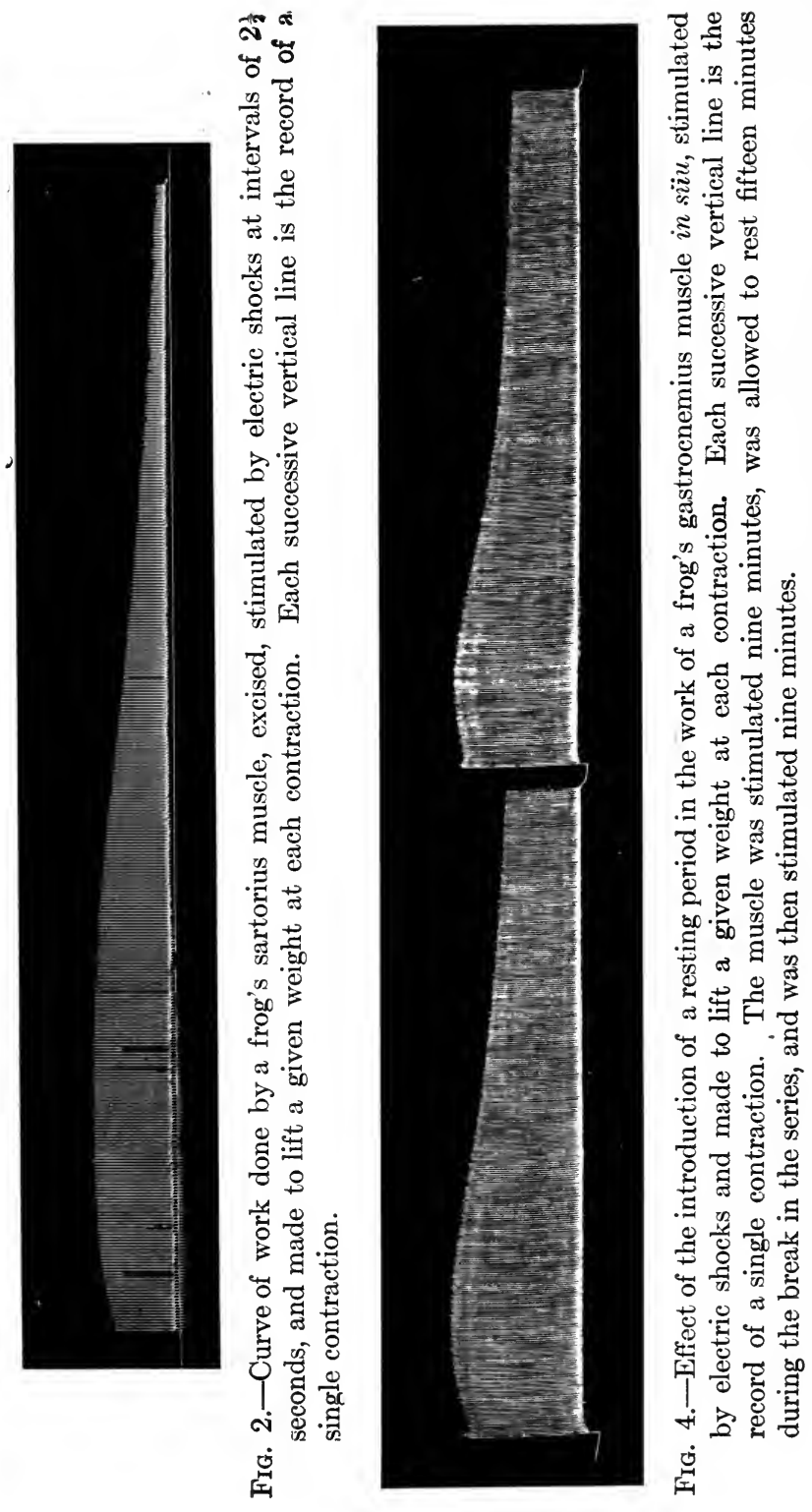


that of the last hour of the morning; but the rise to the maximum is less and the subsequent fall much greater. The output of the final hour indeed is 32 per cent less than that of the maximum for the day, and the total output of the afternoon is 4 per cent less than that of the forenoon.

The interpretation of such a curve on a physiological basis is aided by the consideration of certain other physiological phenomena. The curve of each spell is not unlike the curve of output of a single isolated muscle contracting upon being artificially stimulated at regular intervals and lifting a given load (Fig. 2). In the muscle curve the preliminary rise, called the "treppe" or "staircase," represents an improvement in working power due to chemical and physical changes within the muscle; the gradual fall represents the diminution of working power involved in fatigue, which is due in turn to chemical and physical changes within the muscle. These events within the muscle are purely objective phenomena; in the human machine there are added to the objective muscular contractions the subjective phenomena of the nervous system, which complicates the physiological situation enormously. Nevertheless the apparent similarity between the two curves suggests, although it does not make certain, a similar fundamental interpretation. The rise in the curve of 
output of the human machine is commonly called the "practice effect." It probably represer.ts mainly a real increase in working power, resulting from improved focussing of attention and better neuromuscular coordination, and, were our knowledge sufficiently complete, it probably could be correlated with chemical and physical changes within the body. The fall in the human curve probably consists in considerable part of an actual decrease of working power, caused by fatigue, although a voluntary, wilful lessening of work may enter into it. The increased output immediately after luncheon is the expression of the increase in working power that results from food and rest. The greater final fall in the afternoon, as compared with the morning, spell probably represents in great part the cumulative fatigue of the day.

Certain tests more objective than that of output have recently demonstrated also that fatigue results from the day's work. The spring-balance muscle test (5) applied at the beginning and the end of the day's labor in some of our munition factories shows that the work of the more strenuous operations results usually in a diminution of the total strength of all the workers; in operations requiring moderate exertion only the weaker workers show the effect. A day in which the worker for any intrinsic reason possesses less strength than usual 
is apt to be followed by a day showing more than the usual fatigue; and a day of severe fatigue by one of lessened strength. On days when the strength test shows bigh figures output tends also to be high, and vice versa.

Ryan's (7) vascular skin reaction test consists in making, with a suitable blunt instrument, a stroke on the skin of the forearm and noting by means of a stop-watch the time that elapses between the moment of the stimulation and the moment at which the white streak thus caused begins to fade. This time is shorter in the fatigued person. The test is applied several times daily. The curve of duration of the streak falls during the forenoon indicating fatigue, rises somewhat during the luncheon hour indicating restoration, and falls again to a minimum during the afternoon. If the subject spends the half day resting instead of working, the fatigue fall of the curve does not occur and a rise may result. Professor Ryan is now making, under the Public Health Service, an extensive experimental study of the applicability of this test to the conditions of industrial work.

Kent (8) has demonstrated a certain degree of lessened acuity of both sight and hearing as the result of the day's work in the factory, but how general this is cannot now be said. 
Hastings (1), in a series of observations extending over several months under the Public Health Service, finds that the urine of day workers in munition factories po'ssesses a higher degree of concentration of hydrogen ions in the evening as compared with the morning. That this sign of acidosis is also a sign of fatigue is indicated by control observations on resting subjects, in whom there is a slight decrease in the same ions during the day.

All these recent observations agree in demonstrating by objective methods that fatigue is present at the end of the day's labor and they justify the assumption that the fall in the curve of output is a sign, in part at least, of fatigue. Additional methods of revealing such fatigue are, however, desired. The difficulties of applying any method to industrial workers, who are unacquainted with scientific experimentation and many of whom are impatient of devoting their time to mysteries of the meaning of which they are ignorant, are much greater than with trained laboratory subjects.

Not all curves of daily output are as simple as that presented. In operations that require considerable muscular strength a curve (Fig. 3) is sometimes seen in which for each spell there appears no practice effect, but a continuous fall, 


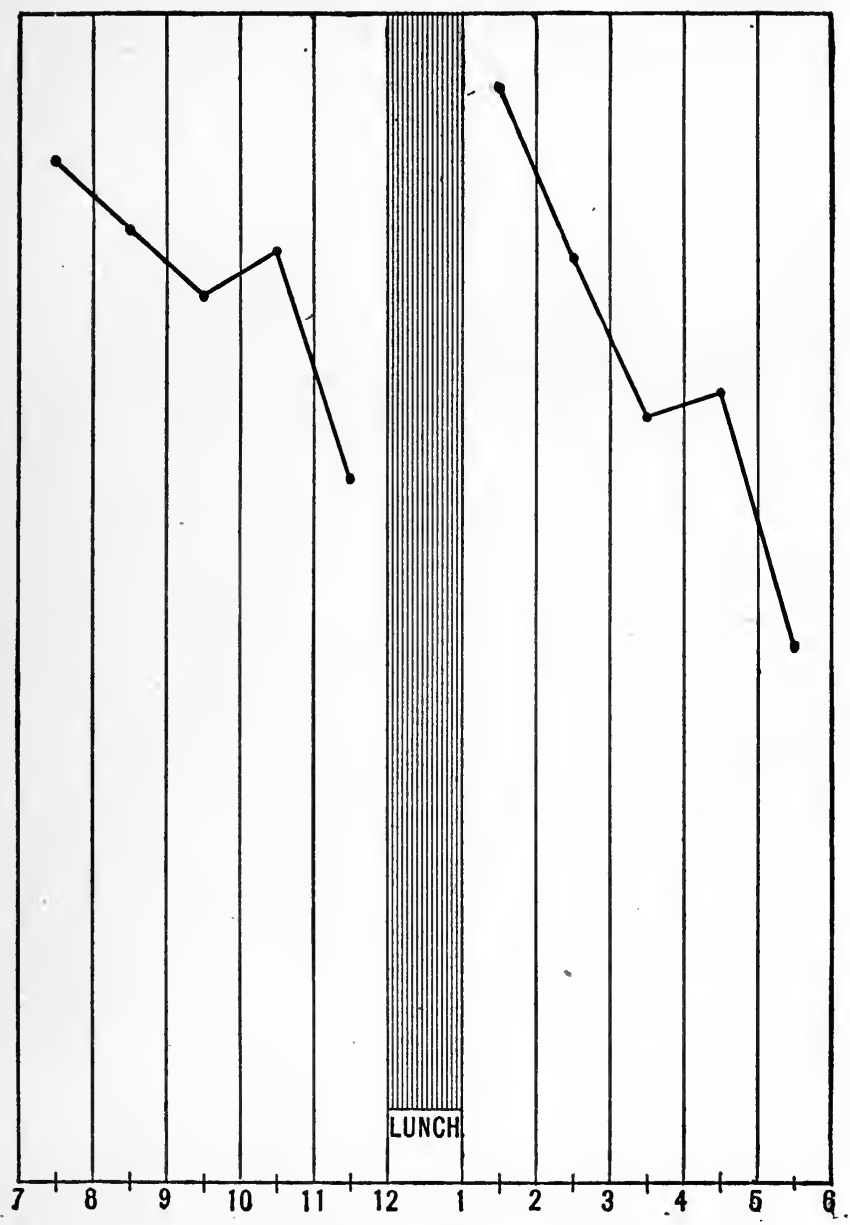

FIG. 3.-Curve of output in polishing metal by hand, an industrial operation that requires considerable muscular strength. The height of each point in the curve above the base line represents the output of the corresponding hour. Men workers; day work; 10-hour shift. (By courtesy of the U. S. Public Health Service.) 
often broken, however, in the latter half of the spell by a brief temporary rise, indicating a spurt on the part of the worker. The fall is often very marked and the significance of the spurt is not clear. Where work is monotonous and interrupted by frequent rests, outputs have been observed the curves of which for each spell are undulating, but show little, if any, distinct fatigue fall. Many other forms of curves have been seen, but sufficient data have not yet been accumulated to allow a classification into types.

The very frequent indication of fatigue in a study of output and the recognition that fatigue is an enemy to high production bring fatigue into great prominence in any study of industrial efficiency (9). A certain degree of fatigue is the expected result of a day's work; it is normal; and when it is not revealed in the output it is questionable whether the individual is approximating his capacity as nearly as he should approach it. When, however, the curve of output does show a falling-off it is not necessarily a sign that fatigue has become excessive and it does not necessarily convey a warning that the output should be cut down. It is always allowable to consider whether output may not even be increased by altering the conditions of the work. 


\section{IV}

\section{SECONDARY SOURCES OF FATIGUE}

IF a search after ways of eliminating fatigue is to be thorough the individual worker should be carefully observed and the conditions of his task should be carefully analyzed. Such an analysis reveals that there are primary and secondary. sources of fatigue. The primary source of fatigue lies in the performance of the essential part of the operation itself involving the transformation of a definite amount of energy. This is the irreducible minimum, stripped of all non-essential accompaniments. It is sometimes possible, as will be shown later, to measure with a fair degree of accuracy the amount of work performed in this essential part of the operation and thus determine the primary fatiguing capacity of the task. This source of fatigue is unavoidable.

But it is different with the secordary sources of fatigue. These comprise certain actions and bodily positions which accompany but are not needed in performing the task, together with certain other environmental conditions under which the task is performed. Gilbreth (10) found that with the 
customary way of laying bricks eighteen motions were employed in laying a single brick, but eleven of these could be omitted altogether, and some of the others could be combined, so that the required motions were reduced to one and three-quarters. The material and the tools which the worker uses are often placed at a distance from his hands and not where he can get them with the least possible movement and expenditure of energy. A worker. is often forced to stand at his work, when he might more economically sit. Stools are less efficient as labor savers than are chairs; and a chair should have an adjustable back. A high chair should be provided with an adjustable foot rest, especially with women workers. The rate of a factory machine run by power is usually set more or less arbitrarily and the worker is expected to conform to it, although his own neuromuscular rhythm, the rhythm at which he can do his best work, may be slower. Such conditions of work, while they may appear trivial, nevertheless, may cause needless muscular contractions, needless or unwise expenditure of energy, and thus may add to the fatigue of the worker. Their avoidance is usually a very simple matter (11).

Other environmental contributing causes of fatigue relate to illumination, ventilation, food, and various sanitary conditions. 
Here may be mentioned lack of sufficient illumination, misplaced artificial lights, and location of workers and machines so as not to secure the full benefit of window lighting. Even when general illumination is sufficient a glare of light on the work bench or the material may be harmful.

Lack of proper ventilation (12) is a frequent condition of unnecessary fatigue. The investigators of the Public Health Service (1) have found that the different members of a group of workers on the same job frequently show similar variations in total strength; and the same is shown by different groups of workers who have different jobs but similar external environments. Such facts indicate that strength is affected by external influences, and the investigators have found that air temperatures of $85^{\circ} \mathrm{F}$., or above, especially when maintained for several days, reduce the worker's strength. My colleague, Dr. Scott, and I (13) have shown by a series of experiments on animals that the heat and humidity of the air diminish muscular power. At an average temperature of $69^{\circ} \mathrm{F} .\left(21^{\circ} \mathrm{C}\right.$.) and an average humidity of 52 per cent the total amount of work that could be performed by certain selected muscles before they were exhausted was regarded as 100 per cent; after the animals had been exposed 
for six hours to an "intermediate" condition of temperature of $75^{\circ} \mathrm{F}$. $\left(24^{\circ}\right.$ C.) and humidity of 70 per cent the total work possible fell to 85 per cent, and after a "high" condition of $91^{\circ} \mathrm{F}$. $\left(33^{\circ} \mathrm{C}\right.$.) and humidity of 90 per cent, the work dropped to 76 per cent. Not only a hot and humid but a still atmosphere is bad; the air of the working place should be reasonably cool, moderately dry, and kept in motion (14). An absolutely constant temperature is not so beneficial as one that is varied. The enervating effect of a high temperature may be much avoided by the use of electric fans. A purely artificial system of ventilation is probably never so efficient as one that makes use also of open windows, with their possibilities of playing upon the skin a variable air supply. Variety is one of the essentials of good ventilation.

Lack of adequate and properly selected and cooked food is a frequent obstacle to high productivity. (See page 84.) The same may be said of a lack of adequate bathing and toilet facilities. The time has gone by when these aids to cleanliness are to be considered as mere needless luxuries. If the human machine is to be in its best working condition it must be kept clean within and without. 


\section{SECONDARY SOURCES OF FATIGUE 23}

While these causes of fatigue are secondary they are none the less real and their elimination conduces to the greater productivity of the human machine. 


\section{V \\ RESTING PERIODS}

The obvious physiological antidote to fatigue is rest. The effect of a resting period in a single muscle is strikingly shown by an easily performed laboratory experiment on an animal (Fig. 4). If the muscle be stimulated by a series of gentle electric shocks a record of its contractions can readily be made on a revolving drum. Such a record shows; after a few minutes, a diminution in the extent of the contractions because of fatigue. If then the stimuli cease, and a rest is allowed, the working power of the muscle is largely restored. The blood has washed out of the tissue the accumulated toxic fatigue substances, has brought to the wearied cells food and oxygen, and they are prepared again to undertake their labor. In such an experiment, which can be performed painlessly upon a frog, the conditions of work are purposely exaggerated, but the principle of the value of resting periods thus illustrated is applicable directly to industrial labor.

In industry the resting period is a necessity, and 
one of the first questions that press for consideration is that of the most advantageous length and distribution of resting in relation to working periods. Mankind long ago decided that the working day should be cut into halves and that one hour of rest with luncheon should separate the two spells; and further that school children ought to have additional recess periods. Industry accepts the luncheon period, often shortening it, however, by one-quarter, one-half, and sometimes twothirds of the conventional hour; but is loath to believe that additional resting periods may be advantageous. The value of the luncheon period in increasing output is sufficiently demonstrated by such graphic evidence as is furnished by Figs. 1 and 2, where there was a pronounced rise in the curve of production following the noon rest. As to the length of the luncheon period both experience and physiology plainly teach, I believe, that it should not be less than one hour whatever the length of the working period. No one can long continue to be proof against the direful effects of the quick lunch.

As to additional resting periods indisputable evidence also has been accumulated of their real value to the employer, by increasing output. The first exact studies in this direction were those of Taylor (15) twenty years ago, who measured with 
a stop-watch the time during which a worker in a given simple operation was actually working. Taylor's subject of observation, Schmidt, bids fair to be one of those immortal characters which we sometimes meet in scientific literature, immortalized because of their submission to experimentation that makes possible important scientific advance. It was Schmidt's task to pick from a pile of pig iron on the ground a single pig, weighing about 92 pounds, carry this up an inclined plank and drop it upon a railway car, and this task was repeated all day long. Though simple it was a heavy muscular task, and Schmidt usually handled about 12.5 tons of iron in the day. Taylor found, by "experiments" he says, although the nature of the experiments is not fully revealed, that in such work a first-class laborcr should be under load only 42 per cent of the day, and free from load during the remainder of the time. With the usual manner of working there was no assurance that this proportion was adhered to. A change was then introduced: Schmidt was put under strict orders; his movements were timed by a stop-watch; and after loading ten to twenty pigs he was required to rest for a definite time. With such a system of alternating work and rest periods it was found that he was able to load in one day, and to continue to load day after day without 
detriment, not 12.5 tons as before, but 47 tons, an increase of 266 per cent.

The investigators of the U. S. Public Health Service (1) have introduced into certain operations in one of our munition factories a recess of ten minutes in each spell of the ten-hour day. The observations are not yet completed, but they show at the present date almost invariably an increase in the output. For example, in a soldering operation three successive periods of two or three weeks each after the introduction of the recess periods revealed an average increase in production of 3,17 and 26 per cent respectively. In another factory, engaged in the manufacture of automobiles, where an eight-hour day prevails and working up to capacity is regularly expected, a tenminute recess, although followed by a temporary acceleration, resulted usually in a slight fall in the average total output of the shift. The American investigators have recognized the difficulties in obtaining exact statistics of the effect of recess periods alone, uncontaminated by that of other possible variables, such as workers, machines, and materials. The value of resting periods in a war operation is strikingly illustrated by a British incident, in which two squads of soldiers, equal in number, were ordered to dig equal lengths of a certain trench. All the men of one squad worked 
continuously and as hard as possible. The men of the other squad were divided into groups, and each group dug strenuously during five minutes and then rested ten minutes. This organized squad easily finished its job first.

The beneficial effect of resting periods on output is thus not to be doubted, although further evidence is desired regarding their optimum duration, number and distribution throughout the working period. They are probably of greater value in strenuous work and work in which long spells prevail. The extensive experience of Vernon of the investigating staff of the British Health of Munition Workers Committee in the study of labor in munition factories has led him to conclude that "A spell of five hours is probably too long for almost any kind of labor." Our own experience in American factories leads to the same conclusion. But with a short working day, and 'especially where production already approximates capacity, the temporary gain resulting from a brief rest may possibly be wiped out by the loss involved in the time actually taken from work. 
THE LENGTH OF THE WORKING DAY

THis brings us naturally to the problem of the length of the working day-perhaps the most vital of all industrial problems in a consideration of efficiency. Here the difference between the non-living and the human machine stands out clearly. Given the proper rate, the proper load. and the proper lubrication, with the non-living machine one hour in the day is as good as another; however long it works, there is no diminution in the amount of its product. It is not so with the human machine, with its curve of output varying with the character of the work and the capacity of the worker, and falling as fatigue progresses. When long hours are imposed upon the human machine the average amount of work done per hour is diminished. This is largely an unconscious process. It is obvious that there is a limit to the working period and it is obvious too that the problem of its proper length is really a problem in human physiology. In attempting to solve this problem nothing stands out more 
clearly than the fact that a longer working day does not necessarily mean a larger output. And yet over and over again the mistake is made of increasing the hours of labor when greater production is desired, just as if the worker's body were a thing of unyielding iron and brass, instead of living and fatiguing tissues. This mistake was made in England at the beginning of the war, when the human machines of the factories were driven until they broke. The attempt to impose the same mistake upon our own war industries is being made from time to time. It is not, perhaps, of chief moment that a few lives are thus destroyed, because destruction of life is a necessary feature of war; but it is forgotten that the war emergency is a matter not of days, but of months and perhaps of years, and that the maintenance of the working power of the industrial worker throughout months and years is as essential to victory as is the existence of the power to-day. It is not, therefore, in the long run economical to make the work of the day so strenuous or so long continued as to diminish the work of the following days and permanently decrease output.

In deciding the proper length of the working period the two factors of the fatiguing character of the work and the capacity of the individual 
workers should be taken into consideration (16). One operation is more strenuous than another and correspondingly taxes the powers of the worker more. Moreover, one worker becomes fatigued more readily than another. Consideration of a period longer than twelve hours may be at once dismissed, for there is sufficient evidence that no one can profitably be employed in any task habitually for a longer time than twelve hours. So too there is little evidence at present that, for most persons capable of urdertaking industrial occupation and for most occupations, eight hours is too long for the work, although I am quite ready to admit that this latter statement may be subject to revision in the future. Discussion may, however, profitably be confined for the present to these limits.

Now it has been frequently and indubitably shown that a shortening of the period from the upper toward the lower limit may increase not only the output per hour, but also the total output. It should here be borne in mind that, while an increase in total production in a shorter time is obviously advantageous to the employer, it is not necessarily disadvantageous to the worker, because the longer resting period that follows gives him a better opportunity for recuperation; there is no evidence that the added fatigue involved in the 
greater expenditure of energy during the briefer but more strenuous labor overbalances this gain. Furthermore, even if the original output is merely maintained or slightly decreased during the shorter period, while the worker still gains physiologically, the employer does not necessarily lose financially, for the cost of production has been materially decreased owing to the saving in the consumption of mechanical power, lighting, heating, wear and tear of machinery, and other sources of expense that vary directly with the length of the working period.

The older studies relating to length of working period and output are well known. Prominent among them, because of the care with which they were followed and the fulness with which they were reported, are the cases of the Salford Iron Works at Manchester, England, the Engis Chemical Works, near Liège, Belgium, and the Zeiss Optical Works at Jena, Germany. At the Salford Iron Works (17) the working week was shortened in 1893 from fifty-three to forty-eight hours for its 1200 employees. The results were unmistakably in favor of the decrease: Production was increased; the proportion of time lost without leave to the total time worked was decreased from 2.46 to 0.46 per cent; and, although, because of a fall in the selling price of the goods, which happened 
to occur during the year of observation, the cost of wages increased 0.4 per cent, this was exactly balanced by a saving in gas, electric lighting, wear and tear, etc. The experiment was a marked success, and assisted in the reduction to a fortyeight hour weekly basis of the work in the British government factories and workshops. At the Engis Chemical Works (18) in 1892 the change was made from a two-shift system of twelve-hour periods to a three-shift system of eight-hour periods, the duration of actual work in the two cases being ten and seven and one-half hours respectively, with the result that in the shorter time the same men at the same furnaces with the same tools and raw material produced as much as before. At the Zeiss Optical Works (19) in 1900 the working day was shortened from nine to eight hours with an average increase of about 3 per cent in the daily output of the employees.

Similar evidence has been accumulating in more

Output of Employees in Shoe Manufacture

\begin{tabular}{c|c|c}
\hline \multicolumn{1}{c|}{ Period. } & Working hours. & $\begin{array}{c}\text { Production unit } \\
\text { per employee } \\
\text { per day, based } \\
\text { on pairs of shoes } \\
\text { shipped. }\end{array}$ \\
\hline October-November.......... & 55 & 8.91 \\
December-January ........... & 52 & 9.00 \\
February-March............. & 52 & 9.02 \\
\hline
\end{tabular}


recent years. An American company (20) employing about 4000 hands, both men and women, in the manufacture of shoes, reduced its weekly working hours in December, 1916, from 55 to 52 , with the result shown in table on p. 33.

The very exact measurements by Vernon (21), under the British Health of Munition Workers Committee, afford most valuable evidence. Reduction of the actual weekly working hours of a group of 56 men, engaged in the heavy labor of sizing fuse bodies, from 58.2 to 51.2 , increased the total output 22 per cent, as is shown in the accompanying table.

Output of Men Engaged in Heavy Work

\begin{tabular}{l|c|c|c|c}
\hline & \multicolumn{2}{|c|}{$\begin{array}{c}\text { Average WegkLY } \\
\text { Hours. }\end{array}$} & $\begin{array}{c}\text { Relative } \\
\text { hourly } \\
\text { output. }\end{array}$ & $\begin{array}{c}\text { Relative } \\
\text { total } \\
\text { output. }\end{array}$ \\
\cline { 2 - 5 } & Nominal. & Aotual. & & \\
\hline First period.......... & 66.7 & 58.2 & 100 & 100 \\
Second period........ & 62.8 & 50.5 & 122 & 106 \\
Third period ......... & 56.5 & 51.2 & 139 & 122 \\
\hline
\end{tabular}

With 80 to 100 women performing the moderately heavy labor of turning aluminum fuse bodies in a lathe, reduction of the actual working hours from a weekly average of 66.2 to 54.8 resulted in a gain of 11 per cent in total output; with a subsequent reduction to 45.6 hours a gain of 9 per cent was still maintained. The following table gives the 


\section{LENGTH OF WORKING DAY 35}

details. Note also the enormously increased hourly output.

Output of Women Turning Aluminum Fuse Bodies

\begin{tabular}{l|c|c|c|c}
\hline & \multicolumn{2}{|c|}{$\begin{array}{c}\text { Average WeEkLY } \\
\text { Hours. }\end{array}$} & $\begin{array}{c}\text { Relative } \\
\text { hourly } \\
\text { output. }\end{array}$ & $\begin{array}{c}\text { Relative } \\
\text { total } \\
\text { output. }\end{array}$ \\
\cline { 2 - 3 } & Nominal. & Actual. & & \\
\hline First period ......... & 74.8 & 66.2 & 100 & 100 \\
Second period ........ & 61.5 & 54.8 & 134 & 111 \\
Third period.......... & 54.8 & 45.6 & 158 & 109 \\
\hline
\end{tabular}

A third instance, illustrated in the table below, is also of interest. Here 40 women performing the light labor of milling a screw thread on fuse bodies were granted a reduction in working time amounting to an actual weekly average of 26 per cent. While their hourly output was increased by the considerable figure of 33 per cent this was just insufficient to maintain the former day's rate, which fell by 1 per cent.

Output of Women Milling a Screw Thread

\begin{tabular}{l|c|c|c|c}
\hline & \multicolumn{2}{|c|}{$\begin{array}{c}\text { Average WEEKLY } \\
\text { Hours. }\end{array}$} & $\begin{array}{c}\text { Relative } \\
\text { hourly } \\
\text { output. }\end{array}$ & $\begin{array}{c}\text { Relative } \\
\text { total } \\
\text { output. }\end{array}$ \\
\cline { 2 - 3 } Nominal. & Actual. & & \\
\hline First period.......... & 71.8 & 64.9 & 100 & 100 \\
Second period......... & 64.6 & 54.8 & 121 & 102 \\
Third period......... & 57.3 & 48.1 & 133 & 99 \\
\hline
\end{tabular}


This result was due to the nature of the task, which was chiefly a machine operation in which the worker was forced to stand idly watching her machine during four-fifths of the time and had less opportunity than did the other workers for quickening her speed.

- These varied results make it clear that reduction in working hours, other conditions remaining unchanged, affects production primarily in proportion as the physiological factor enters into the work. Here operations differ greatly. One is treading on dangerous ground if he attempts to predict an optimum working-day without an analysis of the work itself. The fact is unmistakable, however, that the most reliable evidence at present points toward an approximation of the eight-hour working day as affording for a considerable variety of occupations and for conscientious workers the best condition for high productivity. But the conclusion that an eight-hour day is advisable universally in the industrial world must be regarded for the present as an assumption hardly justified by the facts. The movement toward a universal eight-hour day, now more than sixty years old, has gained great headway and has led to the correction of many abuses. It should now be recognized that the question is one into which physiology should step and that before a 
decision on a strictly scientific basis can be reached much further observation is needed.

Here I would utter a warning against the danger of accepting mere opinion not based upon actual facts. If the effect of a reduction of hours on output is to be determined, it should be determined in the same manner in which the result of any exact scientific inquiry is sought. Conjectural estimates of output are of no value; quantitative measurement alone is decisive. Not until reliable statistics are obtained with the longer working period should the reduction in time be made. Then, in so far as possible, only the time factor should be changed. In both the control and the experimental series of observations, all possible variables but the time factor should be avoided, or should be allowed for if avoidance is not possible. These variables may include the number of employees actually working, the replacement of skilled by unskilled workers, the time lost, a change in the quality of the material, a change in methods of working, and seasonal and other possibilities. Moreover, observations should extend over a period of at least several months before a conclusion is finally drawn. All effort indeed toward determining the effects of a reduction in the working hours in any factory or any industry is wasted unless care is taken to conduct the inves- 


\section{THE HUMAN MACHINE}

tigation after the manner of an exact scientific experiment.*

* The National Industrial Conference Board (54) is engaged in a study of the effect on output of the reduction of working hours in various industries, and has published to date the results of its inquiries into the manufacture of cotton and of shoes. Unfortunately the data were obtained largely by the unreliable method of the questionnaire, rather than by that of exact measurement. Inferences drawn from such data can hardly be accepted as conclusive. 


\section{VII}

CAPACITY AND THE SELF-LIMITATION OF . OUTPUT

There is one feature of labor which I believe to be one of the most potent and most universal foes to efficiency. Natural working power varies infinitely in individuals, and yet no one will, I think, dispute the statement that few persons work up to their individual capacities. Professor William James (22), clear-sighted observer and keen thinker, once said that " As a rule men habitually use only a small part of the powers which they actually possess and which they might use under appropriate conditions." This general human tendency is found also among industrial workers. It is even traditional with many and a thing to be encouraged, especially with those who have worked for years and have become accustomed to the traditional ways of labor. It is sometimes called, in this country, "soldiering" and, in Great Britain, " ca' canny." It may be a conscious, wilful procedure, or it may be partly or even wholly unconscious. Many honest workers will tell you that it is deliberate. It is sometimes ascribed to labor 
unions as a deliberate policy, but it is found among non-union workers as well. The American investigators (1) have found that it occurs very commonly in the form of what they have called "stereotyping of output," that is, a form of output in which the same individual or a group of individuals will turn out day after day and week after week practically the same quantity of finished product. In one munition factory engaged in the manufacture of fuses a large proportion of the force was thus working. In forming at a capstan lathe the large end of the fuse one man finished exactly 1000 pieces on each of 44 nights out of 45 that were observed; in gauging the fuses 5 girls out of 6 that were studied for one week, examined 1315 fuses each day; in 99 cases of drilling certain holes, out of 163 observations extending over seventeen days, 1300 fuses were drilled by each battery of two operatives in each spell, and 2600 in each day; and in another drilling operation the output of each of 16 different workers, night after night, for one week was 3600 , no more and no less. If work were stopped for a brief period for reasons beyond the power of the worker to control, such as the temporary crippling of a machine, the stoppage was likely to be followed by a spurt and, without overworking his powers, the worker finished the day with the usual production to his credit. There is obviously no general form of daily curve that is 
afforded by such an output. It may or may not be accompanied by fatigue. In the factory mentioned, and this seems to be general with rèpetitive work, piece-rates were paid, and the worker by doing more could earn more wages, and yet he limited his work.

The cause of this self-limiting of production is probably quite varied. It is often to be traced to plain laziness. One often finds too a loyal disinclination among capable workers to surpass their fellows, and often a more or less unconscious recognition that a certain amount is enough for a day's work. Sometimes the fault lies with the foreman, who encourages the performance of a certain amount as the traditional and proper output of his department, or as that which conforms best with the routine of the factory. But over and above all other causes the self-limitation of production is to be laid most commonly to a custom that has long prevailed and still prevails in industrial management, that of lowering an established: piece-rate when in the opinion of the management the worker is earning too large wages. Sometimes this is done directly, sometimes it is done indirectly by slightly altering the operation and calling it new, although it may accomplish the same end. This cutting of piece-rates has been so prevalent in the past-it is the boast of one employer that he had cut the rate on a particular operation five times 
in succession-that the experienced worker has learned to expect it when, by his own exertions, his wages run high, and thus his original confidence in his employer has been undermined and his original ambition to work hard, however honest, has been thwarted. The choosing of a proper piecerate for an operation, one that will justly compensate the worker for his services and allow a fair profit to the employer, is admittedly a difficult matter; but with an experienced rate-setter or by the aid of time studies mistakes that involve serious financial loss should rarely occur. On the other hand, the loss of the worker's confidence in the honesty of his employer is of profoundly serious moment, inimical to his best efforts and sure to involve the employer in a decrease of pecuniary profit. Nothing can be more detrimental to the industrial success of both than a feeling of mutual distrust. Their re'ations ought to be those not of opponents in a game, each trying to outdo the other, but rather of companions in an enterprise to be achieved through the best efforts of both. The employer should pay a wage that is directly proportional to the effort that the worker expends, and this once promised should be continued. If this is done the worker is under equal obligation not to limit his production, but to work up to the capacity that is in him. This is especially a duty where he is granted a short working day. 


\section{VIII}

THE MAINTENANCE OF WORKING POWER.

\section{OVERTIME}

I HAVE spoken so far only of the labor of the single work-day and the fatigue that results from it. That there exists also a weekly course of fatigue is generally assumed. There have been few exact studies of this subject, but there is a certain amount of reliable evidence that weekly fatigue regularly exists. Thus Martin, Withington and Putnam (23) have found in students a progressive diminution in the sensibility of the skin from Monday to Saturday, and they ascribe this to the progressive fatigue of the week. The industrial output curve for the week, however, rarely shows the effect of a weekly fatigue. It is persistently low on Monday, higher on Tuesday, and, while usually at a fairly high level with fluctuations during the week, does not necessarily fall on Saturday. The low output on Monday, the socalled "Monday effect," is well recognized and is usually ascribed to Sunday dissipation, especially drinking. A more reasonable explanation is that suggested by Kent (24) that the low output is due 
to a lack of neuromuscular coordination following a day of rest; as the result of the abstention from work at the week-end operations are to some extent forgotten; by the training imposed by the work of Monday, however, they are quickly learned again and the physiological mechanism comes back to its usual state of efficiency. The rise in output from Monday to Tuesday is thus a "practice effect." It may seem strange that the output curve does not fall toward the end of the week; but the absence of a fall cannot be interpreted as necessarily an indication that no fatigue is present. It may merely show that with the conditions under which the work studied has been performed there is not sufficient cumulative fatigue to make itself evident in this particular form of physiological activity. There is always too the unavoidable suspicion that the operatives are not working up to their capacities. There is, moreover, to be considered the fact that the human machine is peculiar in that it is always played upon and its efficiency is partly determined by mental influences, and it is not impossible that the approach of the week end with its expected release from labor may buoy up the workers and mask any tissue fatigue that might otherwise manifest itself. That psychical influences do mask fatigue is well illustrated by the case of the six-day bicycle riders 
in New York, observed by Ayres (25), who rode at an average of 18.8 miles an hour when there was no music, but speeded up to 21 miles when the band played.

In order to preserve the working power daily fatigue should not be so great that it cannot be substantially removed by the night's rest; weekly fatigue ought likewise to be dispelled by the rest of Sunday. If this is not accomplished, if there is a residue of this powerful obstacle to efficiency accumulating from day to day and from week to week, serious results will surely follow. This was precisely the situation in the munitions industry of England. Sixteen months after the war began the British Health of Munition Workers Committee (2) wrote: " Taking the country as a whole the Committee are bound to record their impression that the munition workers in general have been allowed to reach a state of reduced efficiency and lowered health which might have been avoided without reduction of output by attention to the details of daily and weekly rests." And again, twenty-two months later, the Committee wrote: "The conditions are not the same now as they were in the early days of the war; not only have large numbers of the youngest and strongest workers been withdrawn for military service, but those who remain are suffering from the strain in- 
separable from a continuous period of long hours of employment. . . . The effects of the strain may even have been already more serious than appears on the surface, for while it is possible to judge roughly the general condition of those working in the factory to-day, little information is available concerning the large number of workers who, for one reason or another, and often because they find the work too arduous, are continually giving up their job." This experience of England ought to serve as a lesson to other countries, and especially to America.

A particularly insidious way of nullifying the advantages of a short working-day that is not uncommon is the imposition of overtime, keeping the employee for an evening of work after the day's work is done. Here a peculiarity of the human machine is of interest. Mosso (26) showed long ago that fatigue does not increase in arithmetical proportion to the increase in work done, but that added work imposed upon an already fatigued individual is disproportionately more fatiguing and requires a longer time for recuperation. Kent (8) found that the keenness of the sight of industrial workers is diminished in a greater degree by a day with overtime, than by a day of the usual length. When overtime is imposed the further call upon the depressed tissues can, indeed, be answered for a 
while by further action-the human machine can spurt-but the more healthful occupation of the evening, in view of the work of the morrow, would be one of recreation and rest. If overtime is ever thought necessary, as in a real and serious emergency, it should be only occasional and should be followed by an added compensating resting period.

What is said of overtime applies with equal force to Sunday labor following six days' occupation. Here, again, the example of England is instructive. As a direct result of the study of industrial fatigue since the war began the British Committee puts it tersely in saying "It is almost a commonplace that seven days' labor only produces six days' output," and adds that in Great Britain "Sunday labor for men is now greatly restricted in amount and has been practically abolished for women and young persons."

A further matter of importance may here be mentioned. An observant visitor to the factories cannot fail to notice that he rarely sees old men or women among the employees. This is so evident that the presence of an aged worker appears anomalous. There is a widespread opinion that forty-five represents the retiring age for most industrial workers. In an investigation of 1761 brass foundrymen in Chicago in 1911, Hayhurst (27) found that there were but 17, or 0.97 per cent, over 
fifty years of age, and but 180, or 10.2 per cent, estimated at over forty years. The question immediately arises: $/$ What is responsible for the absence of workers beyond middle life; and the answer inevitably comes to mind that the rigor of the game incapacitates them at an age.when human beings are expected still to be doing excellent work. If this is so, the accumulated fatigue of many years is the decisive factor. The remedy would appear to be a diminution in the hours of labor and the installation of other conditions not so severe for the human machine and conducive to its longer usefulness. In a field in which accurate data are largely wanting and an intensive study is much needed, it is impossible to draw decisive conclusions, but the subject offers foo'd for enticing speculation. It may yet prove to be a vital one in the war industries, for the manufacture of war supplies may possibly yet devolve largely upon men and women beyond the age of forty-five. 


\section{IX}

\section{THE LABOR TURNOVER}

There is still another constant feature of occupational work which is a bar to the highest degree of efficiency, namely, the change in the personnel of the workers. This is called the "labor turnover." Its extent is remarkable, practically no factory is free from it, and it surpasses in amount all estimates of those who have not examined actual statistical data concerning it. It is considered such a serious matter that it has recently been receiving considerable attention from employers and industrial administrators. In a recent study of twelve factories in the metal industry, Alexander (28) found that 72.8 per cent of all employees engaged during 1912 were entirely new to the factories in which they worked and that in order to increase the working force by 6697 during the year 42,571 persons were engaged. The change is less among the more skilled than the less skilled workers. But, whether skilled or unskilled, when it is considered that such figures represent machines, human machines, installed and replaced, 
the wastefulness of the process appears evident. No figures are available to show how the war has affected labor turnover, but it seems fair to as= sume that it has increased as the result of war conditions.

The mere pecuniary cost of a great change in the laboring force is a large item, being estimated by Alexander as $\$ 53.92$ for each new employee. This total includes the cost of such features involved in the employment of new workers as the clerical work of hiring, instruction of new employees, increased wear and tear of machinery and tools, reduced production, increased amount of spoiled work, and more accidents. Almost no exact data exist relative to these factors, but the Public Health Service has been able to discover in several departments of a large munition factory a significant parallelism between the number of accidents and the inexperience of the working force. One of the curves is reproduced in Fig. 8 , page 75 . It must be believed that the low output of a new worker contributes the most considerable item to the cost of the labor turnover, and during the present emergency this is a very serious matter. It is, therefore, desirable to seek out the causes of the labor turnover and to apply the remedies, if such there be.

The Public Health Service (1) has obtained the following statistics regarding the reasons for 
employees leaving one of the munition factories during a period of six months:

A-Reason known to firm............

Dismissed (disciplinary)..........

Unsatisfactory.............. 229

Disobedience to orders........ 86

Moral delinquency........... 66

Loafing, staying out.......... 65

Dangerous................. 58

Refusal to work............ 27

Insolence to foreman......... 26

Sleeping at work............ 18

Disobedience to factory rules, e.g., smoking ............... 15

Private circumstances outside factory

Removal from city........... 109

Military call.............. 78

Family difficulties............ 22

Illness.................. 10

Jail..................... 2

School................... 1

Resigned.................. 112

General-" gave notice"...... 87

No place to stay........... 25

Paid off (discharged honorably)....

B-Reason unknown to firm. Employees

absent more than two weeks without notice.................

992

590

222

68

9,442

Here it appears that more than 90 per cent of the retiring force left their employment for reasons unknown to the company. This experience is probably not exceptional. The analysis does not go farther, but many probable reasons at once come to mind. There will always be a certain number 
of long illnesses, deaths, and specific personal reasons not connected with the factory or its management, and there will always be a floating labor element, drifting hither and thither, and never content to remain long in one place. But it is probable that the majority of industrial workers, like other human beings, prefer to find their niche in the world and remain in it. If, therefore, they do not remain long in the place which they have entered it is because there is a lack of adaptation between them as human beings and their environment. This may relate to wages, length of working day, nature of the work and their fitness for it, danger of accidents, physical conditions of the factory affecting comfort and welfare, their foreman or their fellow workmen, or other features with reference to which they do not, or think that they do not, fit. Specific remedies are, therefore, indicated in specific cases, and a careful search for the causes and the application of the proper remedies should constantly be made by the employing company. But, in general, I believe that whatever promotes individual efficiency, whatever enables the individual machine to work in accordance with physiological laws, whatever leads to more complete adaptation of the worker to his task, will lessen his desire to leave it and will lighten the burden of the labor turnover. 


\section{$\mathrm{X}$}

THE INDUSTRIAL EFFICIENCY OF WOMEN COMPARED WITH MEN

The war has increased enormously the total number of industrial workers, both men and women. Factories that formerly employed hundreds now make use of thousands, and new factories springing up here and there make new centers of occupation. A fact that is of special interest is the relatively greater increase in the number of women than of men workers. It is stated (29) of Great Britain that women have been substituted for men in practically all trades and that according to official figures in July, 1917, 1,392,000 women were taking men's places. Women, as never before, are becoming a prominent feature of industrial life, both in this country and the countries of the other Entente Allies. An inquiry is, therefore, pertinent into the efficiency of the woman as compared with the man worker.

Here I wish to utter a word of preface. Thinking persons have long since passed the stage where the question of man's superiority in general and woman's inferiority is discussed-there is no such 
question. It is equally clear that there exist between the sexes marked biological differences, anatomical, physiological, psychological. I shall not discuss the question, which has a real existence, in how far these differences are genetic, inherent in the nature of the individual and transmissible by inheritance, and in how far they are the result of education, training, social environment and opportunity. But it must be granted that the differences in anatomical features, and they are many and profound, are inherited; and if this be so, it is, I think, idle to claim that the main physiological and psychological differences, also many and profound, are chiefly the result of differences in training and social environment. Nevertheless, whatever their origin, the differences do exist and they must be reckoned with in the determination of the relative fitness of the two sexes for industrial work and their relative industrial efficiencies.

The lesser muscular strength of women is obvious. Miss Thompson (30), in summarizing the results of her own and others' tests on various phases of motor ability, the keenness of the senses and certain intellectual qualities, finds that men have a shorter reaction time than women, with a smaller mean variation in the time, a greater rapidity of movement, a slower oncoming of fatigue, and a greater accuracy of movement; while women excel 


\section{WOMEN COMPARED WITH MEN 55}

men in the rapidity of forming new motor coordinations. Men too have a keener vision in the perception of light and finer discrimination in lifted weights, tastes, and the determination of the areas of visible objects; while women are keener in detecting stimuli in skin sensibility, such as touch and pain effected through pressure, in taste, smell, and color, and have finer discrimination in the pitch of sounds and in color. On the whole men excel in motor ability, and women in delicacy of the senses. As to the intellectual faculties men are superior in ingenuity, and women in memory and the rapidity of forming mental associations. The total amount of general information possessed by the two-I am still following Miss Thompson's summary-is essentially the same where they have taken the same course of education, although men are somewhat better informed in scientific and women in literary subjects. My own experience with men and women in the laboratory has shown me-and I think this is almost a universal experience-that women have less initiative and resourcefulness in planning a research or an experimental method, but that once it has been planned they will perform the required experiments with a high degree of accuracy and commendable persistence. If, however, in the course of the work the apparatus that they are using goes wrong 
mechanically, they are not so successful as are most men in discovering the cause of the trouble and eliminating it.

These differences between men and women make it clear that the first pertinent question here is not that of the greater or less general industrial efficiency of the woman as compared with the man worker, but rather the question of what kinds of industrial operations are best adapted to each. Women are obviously debarred from the muscularly more severe tasks. 'In those requiring constant change and a constant call upon a considerable degree of mechanical ingenuity women may not be expected to be so generally successful as men. But with the lighter operations, where the same act is constantly repeated, which make up now a great proportion of industrial tasks, women find a suitable field for their activities. An observer finds a considerable number of women in our munition factories doing lathe work and doing it with apparently the same degree of efficiency as men. The making of both guns and ammunition requires constant inspection of the manufactured parts to insure their accuracy and the elimination of imperfect pieces, and here women have shown themselves particularly capable. Such inspection, which involves not only very careful observation but often very accurate measurement 


\section{WOMEN COMPARED WITH MEN 57}

and in which rapidity of decision and action is required, is now indeed performed chiefly by women. Wherever men and women are working at the same task and one apparently suited to both I do not find that accurate data have yet been secured to warrant an inference as to their relative degrees of efficiency. The general opinion, as I have been able to gather it from a few of the managers of our munition factories, seems to be that in such tasks woman's efficiency equals man's.

The question of relative health must be taken into consideration. Statistics from various countries show that working women are more subject to illness than are working men, their morbidity is greater. The statistics of the Local Sickness Fund of Leipsic (31) for one hundred wage-earning persons observed are as follows:

\begin{tabular}{|c|c|c|}
\hline \multirow{2}{*}{ Age group. } & \multicolumn{2}{|c|}{$\begin{array}{c}\text { CABEs OF AICKNEBS PER } 100 \\
\text { PERBONB. }\end{array}$} \\
\hline & Men. & Women. \\
\hline Under 15 years. . & 38.0 & 29.0 \\
\hline $15-20 \ldots$ & 37.6 & 36.4 \\
\hline $20-25 \ldots \ldots$ & 36.3 & 42.1 \\
\hline $25-35 \ldots \ldots$ & 38.0 & 50.2 \\
\hline $35-45 \ldots \ldots$ & 44.3 & 55.3 \\
\hline $45-55 \ldots$ & 51.7 & 54.3 \\
\hline $55-65 \ldots \ldots$ & 60.2 & 54.9 \\
\hline $65-75 \ldots \ldots$ & 75.7 & 66.6 \\
\hline
\end{tabular}


This excess of illness occurs especially between the ages of twenty and fifty-five, although it seems not to be due to child-bearing alone. Working females younger and older than these age limits show in general less morbidity than do working males. With minor illnesses women continue at their work more steadily than do men. Notwithstanding this fact, the absences of women from their work because of illness are much more frequent than are the absences of men. Thus the Mutual Aid Society of Silk Workers at Lyons (32) reports that between the ages of twenty and forty the days lost by its women members, because of sickness, were more than twice those lost by men. Statistics obtained by the U. S. Public Health Service (33) show that among 16,000 government employees in the Federal departments at Washington in 1914, men lost on account of sickness an average of 4.82 days and women an average of 8.90 days, also more than twice as many. There is a general tradition that the menstrual function causes a periodic diminution of general efficiency in woman's body, but this is hardly supported by the more exact inquiries. One of the latest and apparently most reliable of these, a research performed by Mrs. Hollingworth (34) at Columbia University, in which various familiar tests of the psychological laboratory were used, leads to the 
conclusions that: "Careful and exact measurement does not reveal a periodic mental or motor inefficiency in normal women. .... The variability of performance is not affected by physiological periodicity. No regularly recurring period of maximum efficiency within each month is discernible." Notwithstanding this conclusion, apparently justified from the results that were obtained by the methods used, one of my graduate students, Miss Epstean, in an investigation of the total strength of ten healthy young women, conducted by means of almost daily tests with the spring balance method extending over five months, reveals an average loss of muscular strength of about 5 per cent during the menstrual days.

Women are more susceptible than are men to industrial poisons. There is general agreement that they are more susceptible to the evil physical conditions of industrial life, such as long working hours, hasty meals, constant standing, lack of resting intervals, and so on.

All the considerations here cited combine to demonstrate that the female body considered as a machine is different in certain respects from the male body and that the conditions under which the greatest degrees of efficiency can be secured for the two, respectively, are probably different in certain features. Because of this and because of the 
fact that women have become an indispensable factor in the industrial world there is needed a carefully controlled experimental study of the problem of women's labor from the physiological standpoint. 


\section{XI \\ NIGHT WORK IN COMPARISON WITH DAY WORK}

LoNG ago night work had become an established industrial custom, especially for men. Night work is excusable where the nature of the processes is such that continuous operation is required, where interrupting the series of events essential to the manufacture would inevitably ruin the material already well along in the process of production. Even where a continuous process is not essential night work is understandable, for it can be argued on apparently reasonable grounds that it is uneconomical to allow productive equipment to remain idle for one-half or two-thirds of every twenty-four hours. But at the outset of every discussion of the topic it should be borne in mind that from the standpoint of the human machine night work is always abnormal. Man is a diurnal, not a nocturnal, animal, and any attempts to change his innate habits in this respect are bound to interfere with his physiological processes. Man's body needs the stimulus of sunlight and is adapted to the atmospheric conditions of the day. Some of 


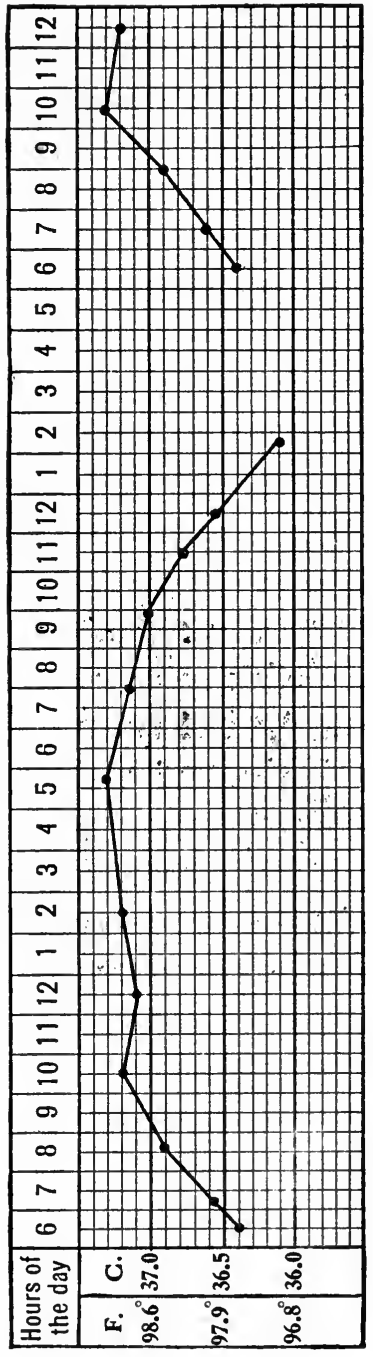

his physiological processes exhibit a regular curve of variation through the twenty-

f four hours, one of the best known being that of bodily temperature, with its gradual rise during the day to a : maximum late in the afternoon, and a gradual fall during the night to a minimum in the early morning (Fig. 5). Under very exceptional circumstances of living this cycle may be reversed by turning the day into night, and vice versa. Thus Simpson and Galbraith (35) obtained such a reversal in monkeys by keeping them awake and active during the night and allowing them to sleep 
in sound-proof and light-proof cages during the day, and Linhard (36) in the long night of an Arctic winter, dark and silent, found that the rhythm of bodily temperature could be reversed at will by changing the alternation of rest and activity. But Benedict's (37) observations are more pertinent to our present subject. By means of an apparatus that recorded the bodily temperature continually throughout the twenty-four hours he observed two subjects, one a customary day-worker who had changed to night-work nine and eleven days, respectively, before the two series of observations were made; and the other a night-watchman who had had five years of uninterrupted night service. In both cases the curves of temperature showed deviations from the curves of an individual living the more normal life, but-and here is the important point-in neither case was there an inversion of the usual day and night curve, in both there was the usual fall through the evening to a minimum in the early morning. It is widely believed that bodily vigor is low in the early morning and that the greatest number of deaths occur then: there is some statistical evidence for this.

The war emergency has increased enormously the amount of night work of both men and women. This is especially so in England. It, therefore, 
becomes desirable to inquire into the efficiency of night in comparison with day work.

A common custom in factories possessing a tenhour working day with no Sunday work is to make the duration of the night work twelve hours for the five working nights of the week, thus equalizing the weekly lengths of the two shifts. The Public Health Service (1) has investigated the output of men engaged in certain operations in one of our munition factories under such conditions and has obtained certain curves of production, one of which is here reproduced (Fig. 6). The operation consisted of drilling and reaming a hole in the bottom closing screw of a fuse, and the task required the use of several tools and accurate muscular coordination. Work began at 6:20 F.M. and continued uninterruptedly until midnight. Luncheon was then eaten, but was allowed to occupy only twenty minutes. The second spell continued from 12:20 until 6:40 A.m. The output of the first spell showed a rise followed by a fall-practice effect and fatigue. The brief luncheon recess was insufficient for recuperation in the work illustrated, although in some other operations observed there was a slight recovery of working power. In the second spell output again rose and then fell during five hours, up to which point the night's curve had not differed essentially from that 


\section{NIGHT WORK AND DAY WORK 65}

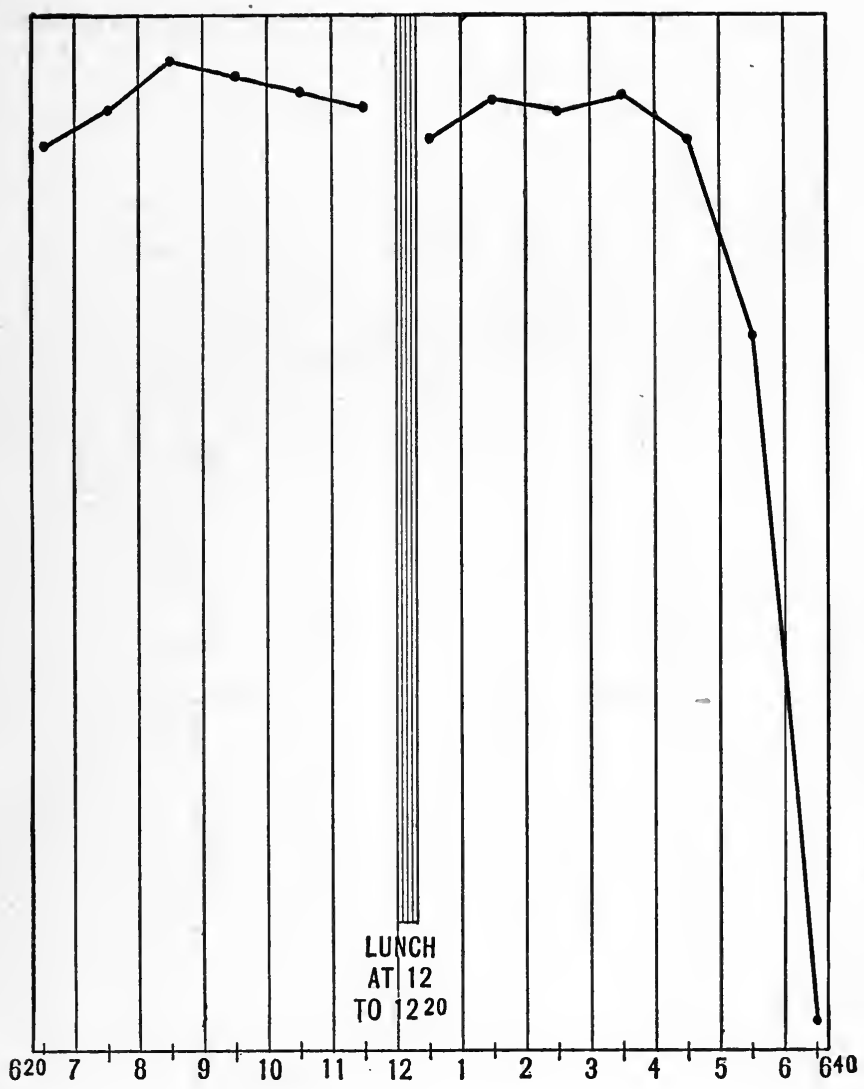

FIG. 6.-Curve of output in night work. The height of each point in the curve above the base line represents the output of the corresponding hour. Men workers; lathe operation; shift of twelve hours and twenty minutes. (By courtesy of the U. S. Public Health Service.) 
of the day for work of a similar character. But then appeared a striking feature, for from about 5 o'clock on, production dropped suddenly and during the final forty minutes almost nothing, in some other operations literally nothing, was produced. The actual figures are here reproduced.

\section{Output of Night Work}

Hour.

$6.20-7$ P.M.
$7-8$
$8-9$
$9-10$
$10-11$
$11-12$

12.20-1 A.M.

1-2

2-3

$3-4$

4-5

5-6

6-6.40
OUTPUT. Drilling and reaming; total of 56 observations.

10,349

10,730

11,220

11,011

10,925

10,591

10,368

10,728

10,677

10,743

10,311

7,932

152

The investigators noted the average time required for performing certain operations during the successive four periods of three hours each throughout the night and found that this gradually lengthened as the night passed on, the successive figures in seconds being 12, 13.3, 16.5 and 17.4. Furthermore, a count of the number of 


\section{NIGHT WORK AND DAY WORK 67}

men found sleeping at every quarter of an hour during the last three hours of the shift gave the following figures, the total number of men working in the department at the time being 74 .

\begin{tabular}{l|c||c|c}
\hline HoUR A.M. & $\begin{array}{c}\text { Number of men } \\
\text { sleeping. }\end{array}$ & Hour A.M. & $\begin{array}{c}\text { Number of men } \\
\text { sleeping. }\end{array}$ \\
\hline 3.30 & 5 & 5.15 & 2 \\
3.45 & 3 & 5.30 & 2 \\
4.00 & 4 & 5.45 & 4 \\
4.15 & 0 & 6.00 & 2 \\
4.30 & 4 & 6.15 & 14 \\
4.45 & 1 & 6.30 & 2 \\
5.00 & 5 & & \\
\hline
\end{tabular}

These results suggest the remedy for the great deterioration in production in the latter part of the night shift: End the work at 5 A.M or even before that and send the workers home and to bed. If this were done and the night work were shortened to ten hours it is quite probable that the night's production would be actually increased.

That, in general, night labor is not so efficient as day labor is clearly shown by certain observations made by the British Committee on the outputs of the two shifts. Thus Greenwood (38) found that where the actual working time was nearly the same in the day and the night shifts of a cartridge factory the women night workers pro- 
duced in the case department in two periods that were observed 17 and 12 per cent less, respectively, than the women day workers, and in the bullet department in one period 10 per cent less. Moreover, the regularity of employment was decidedly inferior with the night workers, they having lost 8.70 per cent of time, as compared with only 5.63 per cent lost by the day workers. In certain operations in the making of 3-inch shrapnel shells by men Vernon (38) found the night workers to produce on the average about 6 per cent less than the day workers. There is a general consensus of opinion that the product of night work is inferior in quality to that of day work and that it contains a larger proportion of spoiled goods.

Statistics show that more accidents occur during the night hours than during the day hours. This is well demonstrated by the observations made by Chaney (39) under the U. S. Department of Labor in a large steel plant during a period of six years, the excess of the night rate over the day rate amounting to 11.6 per cent (Fig. 7).

There is a general consensus of opinion that night work is more deleterious to health than is day work, and this opinion is supported by incontestable evidence; but in the present state of our knowledge it is hardly possible, nor indeed for our 


\section{NIGHT WORK AND DAY WORK 69}

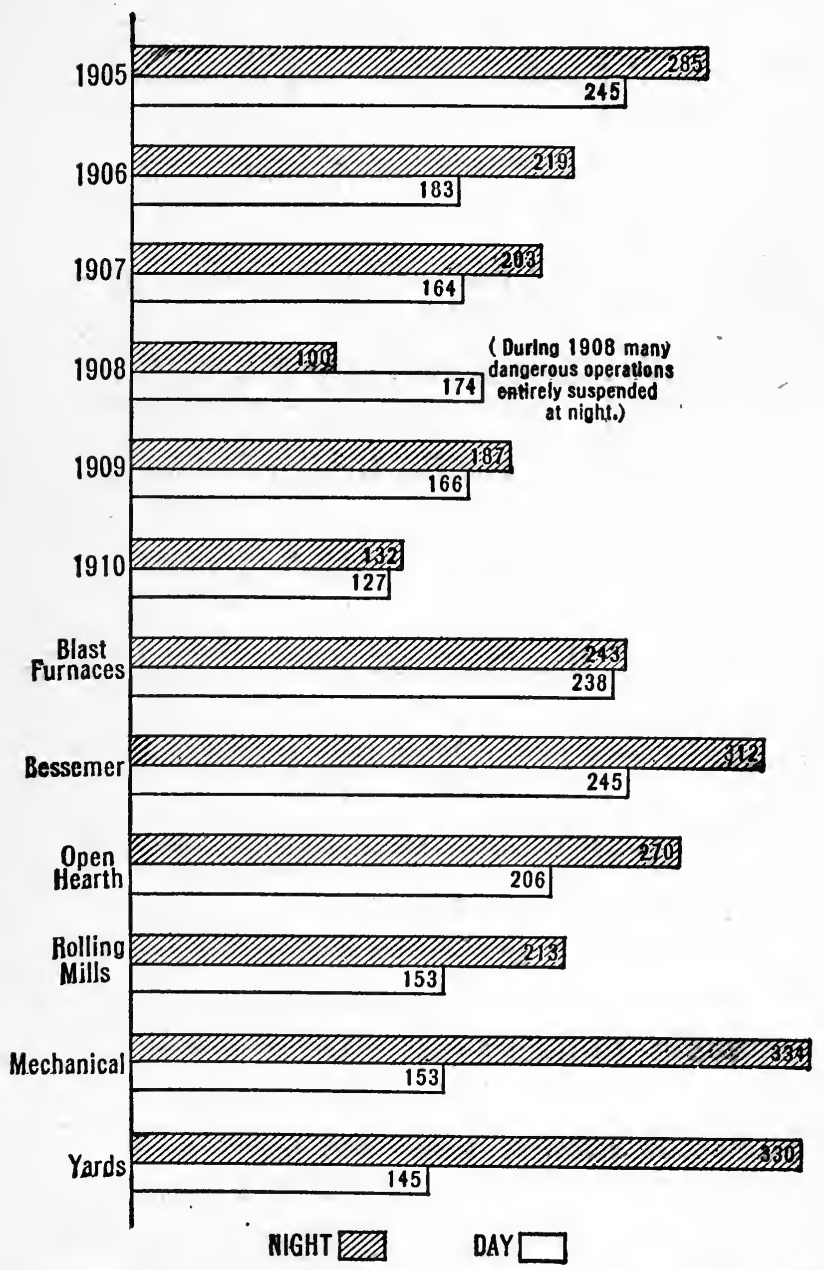

FIG. 7.-Day and night accident rates per 1000 workers in a large steel plant, by years and departments. (By courtesy of the U.S. Department of Labor.) 
present purpose, is it necessary, to differentiate between deleterious effects per se, resulting from such conditions as the attempted imposition of an unphysiological rhythm and the lack of beneficial sunshine, and deleterious effects resulting from the fact that under our social conditions the day's recuperation of the night worker is rarely equal to the night's recuperation of the day worker. Night work entails a diminution of sleep. The day's light, the day's sounds, the irresistible lure of an active world, and, with a married woman, domestic duties, in a home where children must be cared for, meals must be prepared, and clothing must be washed-all these prevent sleep. The New York State Factory Investigating Commission (40) found in one large plant that the married women who worked at night obtained about four and onehalf hours of sleep in the day time. Here in itself is a powerful bar to efficiency. The bad effects of night work on health have been especially observed in women workers, with their greater susceptibility to illness (41). What is a physical tax on man is a physical surtax on woman, and it cannot be allowed that this form of burden is justifiable even in the emergency of war.

I have shown that night work is characterized by certain distinctive features: It imposes on a physiological organism attuned to one sequence of 
events a different and abnormal sequence; it is characterized by greater fatigue than is day work; it is interrupted by sleep; its curve of output falls off at an excessive rate in the morning hours; its total output is less than with day work; its accident rate and its proportion of lost time are in excess over those of the day; it has a deleterious effect on health. All these features are inimical to a high degree of efficiency.

The case against it appears to be black. How can its evils be lessened? The British Committee (38) has suggested one plan, and that is by making it not continuous, week after week, but alternating periods of night work with periods of day work. They have, indeed, observed this plan in women's factories with hundreds of operatives whose work was changed from night to day and vice versa, in some cases every week, in other cases every month. In nearly every group of workers following this plan that were observed, both men and women, there was practical equality of the night and the day outputs, and the total output of the day periods did not seem to be lessened because of the existence of the previous night periods. With women, however, the equality of output appeared to be confined to the more monotonous operations; with those less monotonous there was evidence that the night's inferiority was still maintained. 
The Committee expresses no opinion as to the best length of the alternating periods. Frequent changes have the disadvantage of giving too little time for adjustment of one's habits, especially that of sleeping. If night work must be performed, however, the discontinuous system appears to involve less inefficiency than the continuous system. The American observers have not given special study to the relative merits of the two systems, but their observations point to the general conclusion that a long night shift, such as twelve hours, is unprofitable. The final two hours at least, with their broken time and little output, might well be cut off and the worker be sent home to gain a better recuperative preparation for the labor of the following night. It ought, however, clearly to be understood that these devices of discontinuity and brevity are but a subterfuge; they offer only a mitigation of an evil. Night work is unnatural, unphysiological, abnormal, and it must ever remain so. It should not be allowed for women, and resort to it for men can only be justified by exceptional circumstances. 


\section{XII}

\section{INDUSTRIAL ACCIDENTS}

IN any comprehensive discussion of industrial efficiency accidents to the workers must be considered. It has been estimated that in the United States 30,000 wage-earners are killed annually and at least 500,000 more are seriously injured. By far the greater number of industrial accidents must be laid in part at least to the account of the worker himself rather than to events outside his body, although this fact does not necessarily imply culpability on his part. Thus of 2678 accidents in Illinois in 1910 Bogardus (42) found that 82.2 per cent represented those " in which loss of control, varying from failure to make fine coordinations on to gross and bungling coordinations and to absence of movements which might have prevented injury, appears to have been a factor." In other words, most accidents have, in part, a physiological origin. Of the various conceivable physiological causes two, inexperience and fatigue, are especially potent.

The Public Health Service (1) has found in one 
of our factories a close parallelism between the number of new employees engaged and the number of accidents, and the results of the observations are pictured in Fig. 8. The curves need no discussion. The old and tried worker may become careless at times and, while scorning danger, may fall into it; but it is the inexperienced man who is the more prone to injure himself-a strong argument against a frequent change in the personnel of the workers. Both keenness of attention and precision of movement are impaired in fatigue. Bogardus found by a simple laboratory experiment that uninterrupted work is accompanied by increasing muscular inaccuracy, a result that is indicative of the participation of fatigue in the causation of industrial accidents. This is made very certain by their hourly distribution throughout the working day (6). Most of the tabulations that have been made agree in showing that as output diminishes in each spell, coincident with the progress of fatigue, accidents increase in number-the curve gradually rises through the spell (Fig. 9). The maximum number, however, usually occurs not at the end of the spell, but some time before the end, and during the final hour or more there is a diminution, the curve thus terminating with a fall. This fall is usually ascribed partly to a diminution in the number of workers, partly to their more leisurely 


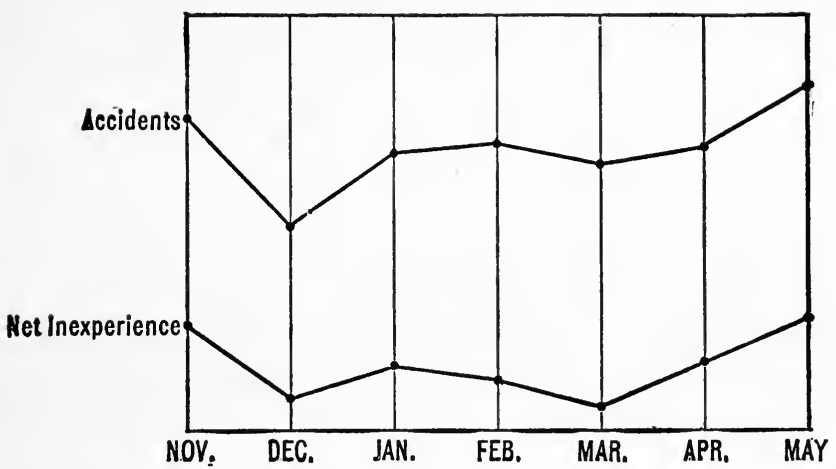

FIG. 8.-Parallelism of number of accidents and number of inexperienced employees in a large munition factory. (By courtesy of the U. S. Public Health Service.)

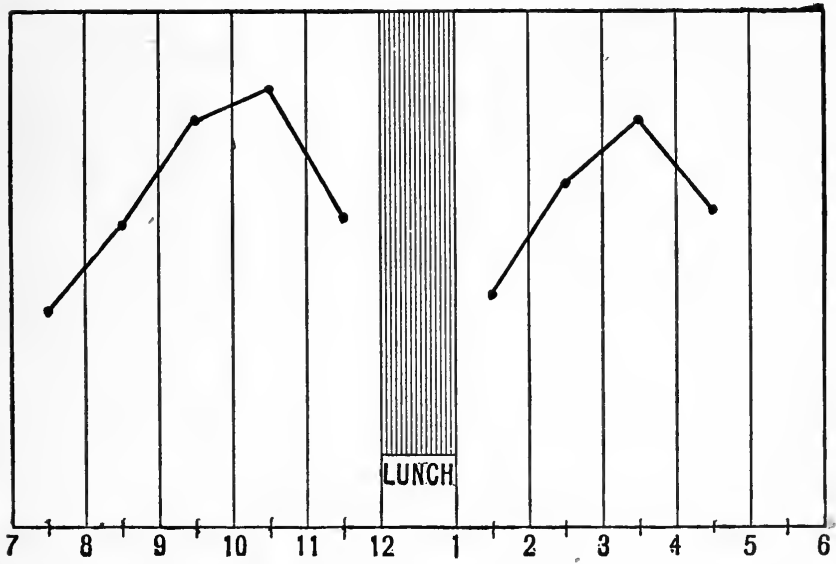

Fig. 9.-Distribution of industrial accidents in the working day. Total of many industries. (Ohio Industrial Commission, Department of Investigation, Report No. 4, 1914.) 
occupation, and partly to the fact that their expected release from labor quickens and makes more precise the action of their neuromuscular mechanism and thus diminishes the chances of a casualty occurring. Whatever the explanation of the final and usually brief fall in the curve, the main fact of the progressive increase in accidents with progressive fatigue exists and is impressive. The worker who is fresh at his work, keenly attentive, and capable of making the proper motions and of keeping out of harm's way may, it is true, inadvertently thrust his hand into the gears, or touch the cutting tool, or step into the path of the hot metal-accidents begin with the beginning of the day's work-but the worker who is tired omits the finer neuromuscular coordinations, makes the grosser and more bungling movements, or altogether neglects the things which physiologically he ought to do-his fatigued condition is largely responsible for his mistakes.

Accidents are increased in number by poor iliumination. The British Departmental Committee on Lighting in Factories and Workshops (43) has found that accidents are far more numerous with artificial than with natural lighting, rising in some cases of the former 40 per cent above those of the latter. This probably accounts chiefly for the greater preponderance of industrial accidents in 
the winter as compared with the summer months, a fact also pointed out by the Committee.

The greater number of accidents occurring during night work than during day work has already been mentioned (p. 68). It is not clear in how far this difference is dependent upon the physical condition of poorer illumination and in how far a depressed physiological condition is responsible.

Accidents, however caused, are a serious bar to the efficiency of the human machine, quite apart from their direct pecuniary cost to the employer. In proportion to the severity and in accordance with the nature of their injuries injured workmen lose time and productive power. If wholly incapacitated, whether permanently or not, their places must be filled by others, and here production is delayed by the necessary training. It is obviously to the interest of the employer to reduce the workers' injuries to their smallest possible number, and the employer has it in his power to prevent a large proportion of them. It must, nevertheless, be recognized, I believe, that, however much employers may have a wholesome regret for the occurrence of accidents to their workers and however much they may realize the expense caused thereby, many of the employers fail to appreciate both the great wastefulness and hindrance to production involved in such casual- 
ties and the ease with which they may be diminished in number. One of the most obvious preventive measures is the installation of safety devices, which are now numerous, varied, effective, and often inexpensive. No really progressive manager will neglect them. Whatever will reduce the labor turnover will reduce accidents. But the avoidance of excessive fatigue is of prime importance, and this can be done by means of the various provisions against fatigue that are here advocated, such as not overdriving, allowing rest pauses, shortening a long working period, and other measures. 


\section{XIII}

INDUSTRIAL MEDICINE. WELFARE WORK

IT goes without saying that an efficient body must, in the long run, be a body free from disease. In so far as the causes of disease lie in the conditions of industrial work their existence has no justification, either ethical or economic; and yet an examination of any of the excellent existing treatises on industrial diseases (44) will make one keenly aware of their great prominence in the life of to-day. Here again fatigue must be recognized as one of the chief factors. Several years ago, while on a railway trip to one of our state capitals for the purpose of opposing proposed unwise legislative action against scientific medicine, a valued friend of mine, one of the leading American pathologists, expressed to me his firm conviction that in the course of time fatigue would be recognized as one of the main causes of disease; and $\lfloor$ Sir James Paget is quoted as writing "You will find that fatigue has a larger share in the promotion or transmission of disease than any other single causal condition you can name." Here may be 
mentioned an instructive research by Abbott and Gildersleeve (45), who found that when rabbits

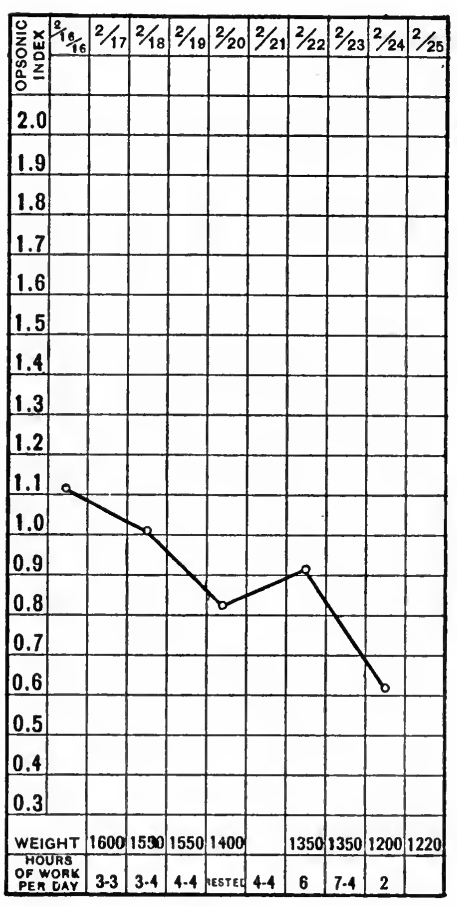

Fig. 10.-Effect of fatigue on the opsonic index of a rabbit. (Abbott and Gildersleeve.) were inoculated with pathogenic bacteria and were then fatigued by running several hours each day in a wheel they died, while other rabbits, inoculated, but not fatigued, survived. With the fatigued rabbits the opsonic index, which may be interpreted to the layman as that condition of the blood which s:gnifies the degree of susceptibility of the organism to bacterial infection, was gradually reduced as the fatigue progressed. Cessation of the fatiguing process for even a day resulted in a partial recovery of depression in the opsonic index (Fig. 10). The bearing of such an experimental 
result on the causation and the prevention of infectious diseases in industrial work is sufficiently obvious. The identification and treatment of industrial diseases and the appreciation of industrial hazards to health and ways of preventing them, are parts of the general modern recognition of the importance of the individual and the duties of society toward him. Here the doctor, the philanthropist, and the legislator have worked in helpful partnership, and the industrial employer cannot afford to refuse his cooperation.

An additional word may be said of a specific phase of these endeavors that has been coming into prominence in recent years under the general title of "welfare work." A recent writer (46) has thus summarized its activities: "With reference to the physical condition of the wage earners, welfare work includes such things as good air and light, lockers for clothing, dressing rooms, baths, the provision of wholesome food for the midday meal, rest-rooms for women, medical examinations, first aid to the injured, free hospital beds, visiting nurses, opportunities for organized athletics, and vacations with pay. Under the head of economic agencies it includes such things as shop schools, technical lectures, and the circulation of technical literature; prizes and bonuses for suggestions, and for length and regularity of service; 
sickness, accident, and old-age pensions; improved housing facilities, and agencies for the promotion of thrift. Upon general moral and social conditions it exerts an influence, not only through the abovementioned channels, but by means of amusement facilities, such as concerts and entertainments; by clubs and societies; through the influence of a social secretary; through the precautionary exclusion of undesirable persons; and through the agency of artistic surroundings, not only within doors, but as the result of the landscaping of the factory grounds."

Such a comprehensive program for human betterment is commendable, and most, if not all, of its features are practicable. The importance of welfare work is now generally recognized, and it is being gradually installed as an essential part of industry. Its name "welfare work," is, I think, somewhat unfortunate, for it contains an implication of a repellent excess of virtue. Its too zealous or too precipitate imposition upon an unwilling body of employees has, at times, aroused opposition among them, and their lack of appreciation or positive rejection of its benefits has, at times, led employers to abandon it after a trial. But such failures should not blind one to its real value. Welfare work should not be too rapidly developed in a factory; it should avoid arousing the suspicion 
that it is a gift, carrying with it the secret expectation that it is to be paid for by increased production; it should not seem too paternalistic; it should not pry too much into the worker's private life; it should not seem to be imposed upon the worker; but it should be established and administered as a bond of mutual helpfulness between employer and employee.

All bonds of such a nature, all things that lead to the advancement of the health and contentment of the worker and promote his good will, all these act as lubricants to the human machine and are indispensable to its highest efficiency. 


\section{XIV}

FOOD $^{1}$

THe human machine like other motors must be supplied with fuel, and this should contain, in latent form, at least the amount of energy that is to be transformed, partly in the performance of the work and partly in maintaining the heat of the body. But unlike other motors, which require but one kind of fuel, such as coal or gasoline, the human machine can thrive best when it has various kinds, and these are known as food-stuffs. While there is considerable difference of opinion as to the most advantageous proportion of human foodstuffs a reasonable combination of the three main varieties is that in which proteins supply about 15 per cent of the required energy, and fats and carbohydrates the remainder, the carbohydrates contributing much more energy than the fats. Persons who are engaged in muscular activity require more food than do those living a sedentary life, and the added amount required is, in general, proportional to the added amount of energy that is expended; here the added amount can be supplied best by added fats and carbohydrates, espe-

${ }^{1}$ See Bibliography (47). 
cially the latter. The relation between occupation and fuel requirement is illustrated by the following table which has been compiled from various authorities (48).

\begin{tabular}{|c|c|c|}
\hline Occupation. & Calories. & Source of calculations. \\
\hline Clerk at desk. & 2250 & Atwater and Bryant \\
\hline $\begin{array}{l}\text { Sales clerk, machinery watcher, } \\
\text { house worker. . . . . . . . . . }\end{array}$ & 2500 & \\
\hline Light, muscular work. . & 2800 & Atwater and Bryant \\
\hline Carpenter, mason.... & 3200 & Tigerstedt \\
\hline Farmer............ & 3500 & Lusk \\
\hline Excavator... & 4000 & Tigerstedt \\
\hline
\end{tabular}

Probably most men working in munition factories require a daily income of energy measured by $3000-4000$ heat-units, or calories, while the working woman's requirement is $80-90$ per cent of that amount or even less.

Mrs. Rose (49) has suggested the following day's food plan for a working man doing severe work.

Fuel Requirement: 3500-4000 Calories.

\section{BREAKFAST.}

Calories.

Cereal (oatmeal, cornmeal, etc.; fried occasionally).......................... 150-300

Sausage, or salt fish, or liver and bacon....... 200-300 Toast, or muffins, or cornbread ............ $300-400$

Oleomargarine....................... 150-300

Milk for cereal and coffee................ 100

Sugar for cereal and coffee............... $\quad 100$ 


\section{LUNCHEON.}

Beans, peas or lentils (baked, or in soup or stew), or macaroni and cheese, or cheese .......... 200-400 Bread (rye, graham, white, etc.). ......... 200-400 Fruit, fresh or as sauce (bananas, apples, apricots, prunes)......................... 100-150 Cake or pie...................... 200-400 Milk and sugar for coffee................ 200

$1000-1400$

Dinner.

Meat pie, or stuffed meat and potatoes, or meat stew with dumplings................. 300-400 Savory vegetable (onions, tomatoes or cabbage) 100-200 Bread............................ 200-400 Suet pudding, or bread pudding, or creamy rice

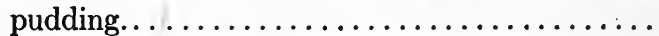
Milk and sugar for coffee.................

If the proper amount of fuel is not provided for the human machine the proper amount of work is not obtained from it in the long run-this result is just as certain as it is with the non-living motor -lack of fuel leads to fatigue and diminished production. Moreover, it is not sufficient simply to provide the proper amount, but it is imperative that it be provided in a digestible state-indigestion conduces to fatigue and thus helps to limit output. It is thus directly advantageous to both the employer and the worker that the latter be 
properly fed. The worker is rarely acquainted with scientific dietetics and, because of his lack of knowledge of what constitutes a balanced ration, of skill in buying, and of wise ways of cooking, if left to his own judgment, he is more apt to be ill fed than well fed. Here the employer can perform a real service. In attempting to reform the worker's nutritive habits in his own home the employer is, perhaps, limited to education and the giving of advice, but at least one scientifically prepared meal can advantageously be served to the workers at the factory. The reasons for this are many. The American investigators (1) have found that a considerable proportion of the workers in the munition factories come to the plant in the morning without breakfast, having risen early and perhaps travelled a long distance, and then work through the first spell without any food whatever. Restaurants in the vicinity of a factory are apt to be inadequate in size and equipment. Food brought from home in a lunch box must be cold and is often ill balanced from the nutritive standpoint. If the worker's home is near enough to tempt him to go to it, he cannot profitably do so if the greater part of his time must be spent in travelling to and fro and only a small remainder is left for a quick and hence indigestible bolting of his food. These facts 
have appealed to many progressive managers, and the luncheon provided at the factory is now common. To secure the best results it should be planned by a scientific dietitian, and every effort should be made to enable the worker to secure a perfectly balanced ration. Care should be expended in procuring the proper quality of foods and in preparing them in an appetizing and digestible form. They should be served in a diningroom and not in the factory work rooms. Service should be prompt, and probably the accepted method of the cafeteria is best. Adequate time should be allowed for eating. The prices charged should be low enough to make it advantageous to the worker to seek this meal rather than one from neighboring restaurants or from his own lunch box. If the employer feels that he must have a pecuniary return from this addition to the worker's comfort he should seek his profit from increased production and a better maintenance of working power, rather than directly from the sale of food across the canteen counter. The British Committee has been much impressed by the good results following the establishment of industrial canteens. They say: "These benefits have been direct and indirect. Among the former has been a marked improvement in the health and physical condition of the workers, a reduction in sickness, 
less absence and broken time, less tendency to alcoholism, and an increased efficiency and output; . among the latter has been a saving of the time of the workman, a salutary though brief change from the workshop, greater contentment, and a better midday ventilation of the workshop." 


\section{XV}

\section{SCIENTIFIC MANAGEMENT}

THE most promising method of promoting efficiency that has acquired prominence in recent years is that which is called commonly " scientific management" (50) and frequently "efficiency engineering; " an occasional name is " Taylorism," a title that appears more often in the European than the American literature. The method originated with the American, Frederick W. Taylor, and has been gradually developed during the past forty years. Over it there has been a heated controversy, with fervid zealous advocates on the one side, the more extreme even looking upon it almost as a religion, and on the other bitter opponents. Out of it has grown the new profession of the efficiency engineer, the industrial engineer, or the industrial counsellor, and the system has been introduced into a considerable number of industrial establishments in this country, which are said (1915) to include some eighty different industries.

In both the principles and the practices of scientific management there is much diversity; nevertheless, certain features stand out promi- 
nently. In it specialization is carried to a high degree. It requires a relatively large administrative staff, and the work is planned, even in its minutest details, by this force. Endeavor is often made to secure only especially competent workers and those specially adapted to the tasks to be performed. A careful analysis of each task is made and each worker is limited to a single operation. In performing it unnecessary motions are omitted. A time study by a stop-watch is made and the average time is determined by which competent workmen can perform the operation. This becomes the standard time for the operation, and all workers are expected thereafter to conform to it. Full and exact instructions are given for the performance of the task in the manner desired. Much attention is given to standardizing tools and other equipment and adapting them exactly to the work. By some system of wage bonuses endeavor is made to induce the worker to speed up to his maximum, and often he is penalized if he falls below the standard set. By carefully planned routing and scheduling the material to be used is always at his hand, and no time is lost needlessly in waiting for material or in passing it on from one worker or department to the next. The advocates of scientific management profess loudly against fatiguing or exhausting the worker. 
The results of the employment of scientific management on production are said to be remarkable. While in a cotton factory production was increased only 20 to 30 per cent, the increase in a factory manufacturing certain special forms of machinery was reported as 100 per cent, in a government arsenal 150 per cent, in the process of bricklaying 170 per cent, in a second machine factory 200 per cent, in the process of shovelling 268 per cent, and in the handling of pig iron 280 per cent. Mr. Taylor thinks that with scientific management it is "safe and conservative to say that the output of the individual workman has been, on the average, doubled."

When one reads the glowing accounts of the theories of scientific management and hears of results like these mentioned the first effect is a feeling of profound admiration for the manner in which the system has been logically thought out, urged upon the industrial world, and put into practice. Here, at last, seems to be the long-sought method by which the trying problem of efficiency is to be solved. It is only when one gains a more intimate acquaintance with the differing theories as promulgated by different leaders and with the differing modes of application of the method does the illusion of perfection become somewhat dimmed. 
No two of the acknowledged leaders in scientific management, Taylor, Gantt, Emerson and others, agree upon its fundamental principles. Moreover, when the principles come to be put into practice there is lacking the exactness which the claim to be "scientific" would seem to require. For example, in engaging workers and assigning them to their tasks no specific and exact tests, physiological or psychological, are used to determine the worker's fitness; the methods used are not essentially different from the conventional methods used in non-scientific shops. In making time studies of a specific task for the purpose of determining a standard time for its performance, sometimes only the fastest workers are selected, sometimes only the slowest, sometimes only the average. Moreover, when time measurements have been made by the stop-watch the so-called " necessary" time for doing the task is calculated. In making this calculation different methods appear to be followed: sometimes the average of all the figures is used, sometimes the median, sometimes the most frequently recurring figure, sometimes the minimum; and sometimes the figures obtained are arbitrarily manipulated to obtain finally the "necessary" time. Allowances are then made for various modifying factors, such as necessary delays, machine breakdowns, possible 
errors in observation, etc.-into all of which the unmeasured judgment of the observer enters. The resultant standard time represents thus a combination of exact measurement and inexact judgment, which may vary greatly with the personal equation of the observer. In setting tasks adequate attention does not appear to be given to the natural physiological differences of individuals. In fixing rates of payment the current market rate for the locality, instead of the expected output or the expected degree of efficiency, is usually taken as the basis, and there is rarely any guarantee that the rate will not be cut if the wages for the operation mount to an alarmingly high figure. There appears to be no reliable evidence that employees under scientific management are overworked, nevertheless in deciding whether fatigue is present, no exact tests are made-indeed, the leaders, while talking much of fatigue, do not appear to have any adequate knowledge of the physiology of the phenomenon, as is illustrated by the statement of one that "Fatigue is due to a secretion in the blood." Furthermore, usually no careful and adequate precautions are taken, such as the introduction of resting periods, to avoid the incidence of fatigue. Little or no consideration is given to the length of the working period-one of the leading prophets is reported indeed as saying that this is a moral question! The practice of 
scientifically managed shops in the matter of guarding the worker against the possibility of injury by accidents does not appear to be essentially different from that in other establishments.

Facts like these do not oblige us to condemn scientific management as a whole, but they cannot fail to cast doubts on the divinity of its prophets and make one suspect that their claims concerning the value of their principles are somewhat exaggerated. Thus, while scientific management is to be highly commended for what it has accomplished in organizing the administration of industry and in improving the material equipment with which industry works, in its dealings with the human machine it falls far short of an ideal., It does not relieve the prevailing ignorance of the human machine that is shown by the factory management, nor does it offer a panacea for the correction of evils that oppose the highest development of human efficiency. It is, indeed, perhaps the most important of all modern movements that have as their object the general promotion of industrial efficiency, but, like all specific systems that attempt glowing reforms in human activity, of which the history of medicine offers a succession of instructive examples, it is, I believe, destined to pass away as a system, while contributing whatever of good it possesses to the common stock of agencies in industrial advance. 


\section{XVI}

THE PHYSIOLOGICAL ORGANIZATION OF WORK

There is one element, which has been mentioned in scientific management, that deserves further consideration by us, namely, the analysis of industrial operations from the physiological standpoint. This analysis has usually been carried on, especially by the followers of scientific management, by means of simple ocular demonstration, a method that is obviously imperfect. Gilbreth (11) improved this by using the cinematograph with various mechanical devices added. Several European physiologists have employed the accepted methods of the physiological laboratory. Among these are Imbert and Amar. Imbert and Mestre (51) connected a loaded baggage truck to tambours recording on a revolving drum and thus obtained records of the motions involved in handling it (Fig. 11). In transporting sacks weighing 60 kilograms along a horizontal cemented grourd they found that in a ten-hour day the work of a man would equal the sum of the following items:

1. A vertical ascent of 70 meters.

2. A horizontal course of about 30 kilometers. 


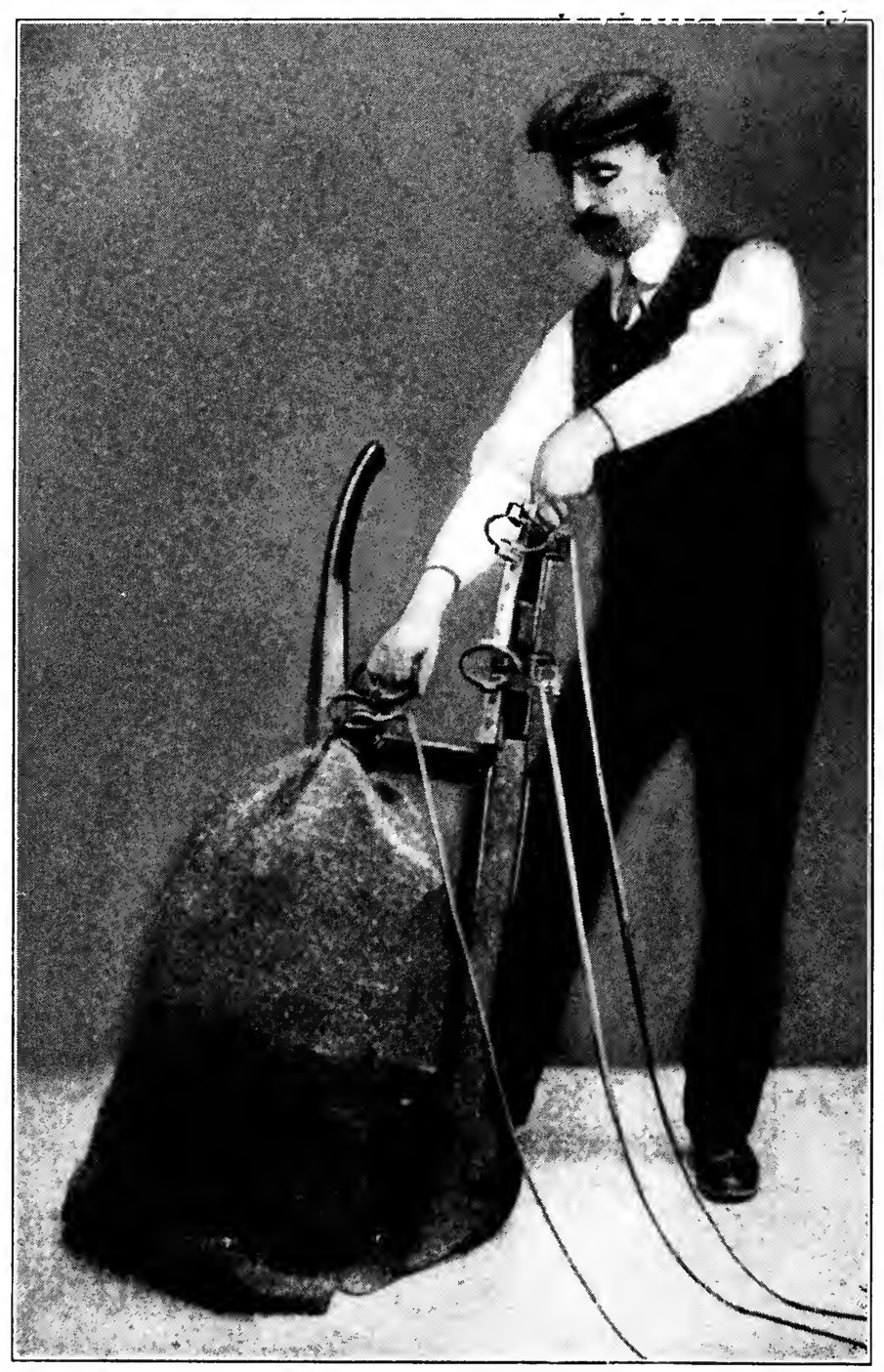

FIg. 11.-Illustrating a method of physiological analysis of an industrial operation. (Imbert and Mestre.) 


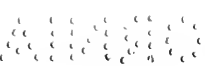


3. The movement through these distances of a total load of 18,600 kilograms by the muscles of the arms.

They found further that the fatigue resulting from one hour of this work is still far from being dissipated by an absolute rest of two hours. They think it entirely feasible to make the principle of the method generally applicable to industrial operations.

Amar (52) has placed tambours over the various muscles and has recorded their contractions. $\mathrm{He}$ has also registered the beats of the heart and the movements of respiration, as to both rate and intensity, and the amount of the gaseous exchange in respiration. From the latter he has calculated the energy expended. He has also made use of the cinematograph. He has thus endeavored to determine with a fair degree of mathematical exactness for various fundamental operations the physiological requisites for maximum production with minimum fatigue, in other words, the most economic physiological attributes of the work. Thus, for the simple operation of filing metal he finds that to obtain the best results in the filing of brass with a half-round file, 35 centimeters in length, the following conditions are essential:

The body of the subject should be vertical, without stiffness, distant $20 \mathrm{~cm}$. from the vise, and the latter at the height of 
the navel; the position of the feet should be such that their angle to one another should be $68^{\circ}$ and the distance between the toes of the two feet $25 \mathrm{~cm}$.; the left arm should be completely extended and should bear down upon the tool a little more heavily than the right arm- $8500 \mathrm{~kg}$. and $7500 \mathrm{~kg}$., respectively. The return of the file should be by a simple sliding motion, without any pressure from the arms; the rhythm of the movement should be about 70 per minute. With these conditions fulfilled, the operation should continue five minutes and be followed by one minute of complete rest during which the arms should hang at the sides of the body. Respirations and heart beats, respectively, should not increase more than 25 and 20 per cent in rate in comparison with their figures at rest. The local fatigue of the forearm is then endurable and general fatigue is hardly felt. Under these conditions, the maximum work is at least twice that of most workmen. In seven hours of such effective work $600 \mathrm{gm}$. of brass filings should be obtained.

This is the ideal physiological picture. Most workmen do not attain it, but rather give a median result with movements of fair regularity. With the novice, however, the position of the body is bad (Fig. 12), the muscular movements are irregular, awkward, badly directed, too intense, and too sudden, and breathlessness and temporary fatigue appear and require too early cessation of the efforts (Figs. 13 and 14). Amar has similarly analyzed the work of planing wood, transporting burdens, such as the soldier's equipment on a level and up an incline, bicycling, spading the earth, wheeling a barrow, etc. 


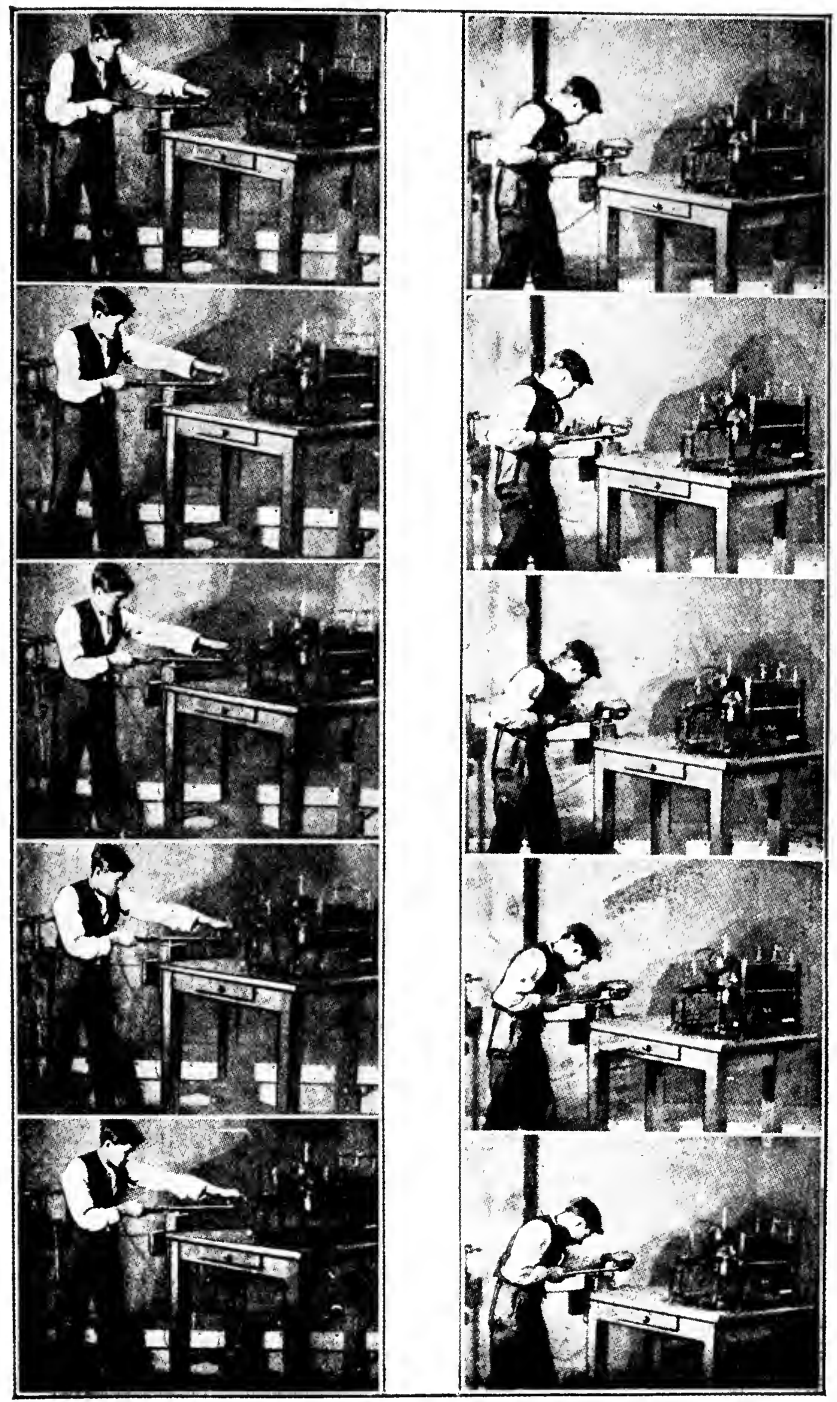

Fig. 12.-Physiological comparison of the trained (left) and the untrained (right) worker in the operation of filing. (From Amar, Organisation Physiologique du Traiail.) 
,

.

$j$ 
Such investigations as these offer an enticing field of study for the physiologist. Their value in demonstrating that ideals can be made realities cannot be denied; but it is impossible at present to foretell their full utilitarian value. If, as some of the followers of scientific management anticipate, specialization in industrialism is to be carried to an extreme, if there are to be no skilled workers in the future, if the unskilled mass can be trained in a few minutes to perform the operation that is to win the worker living wages and more, the more exact methods of training would seem superfluous and uneconomical. But, if, as many prophetic thinkers maintain, there is still to be a place for vocational education it can only be completely satisfactory when it is placed on a sound physiological basis, and in such case there is need of a great extension of the physiological analysis and organization of specific tasks. 


\section{XVII}

\section{SUMMARY}

What now are some of the conclusions that we are justified in drawing from the present tendencies of research concerning ways in which industrial efficiency and productivity can be promoted? The qualifications of prospective workers should be determined so far as possible by exact tests, and workers should be assigned to tasks in accordance with their qualifications. A feeling of mutual confidence should be established between the management and the worker, and nothing should be done by either to destroy that feeling. The worker should not wilfully limit his production, but should work according to his capacity. Wages should be adequate for work done, should enable the worker to live decently, and once fixed should not be lowered if the worker is competent to earn the rate agreed upon. The length of the working period should tend toward a shortening rather than a lengthening, and each of the two spells should be broken by at least one recess period. The luncheon recess should not be less than one-half hour, 
,

$=$ 


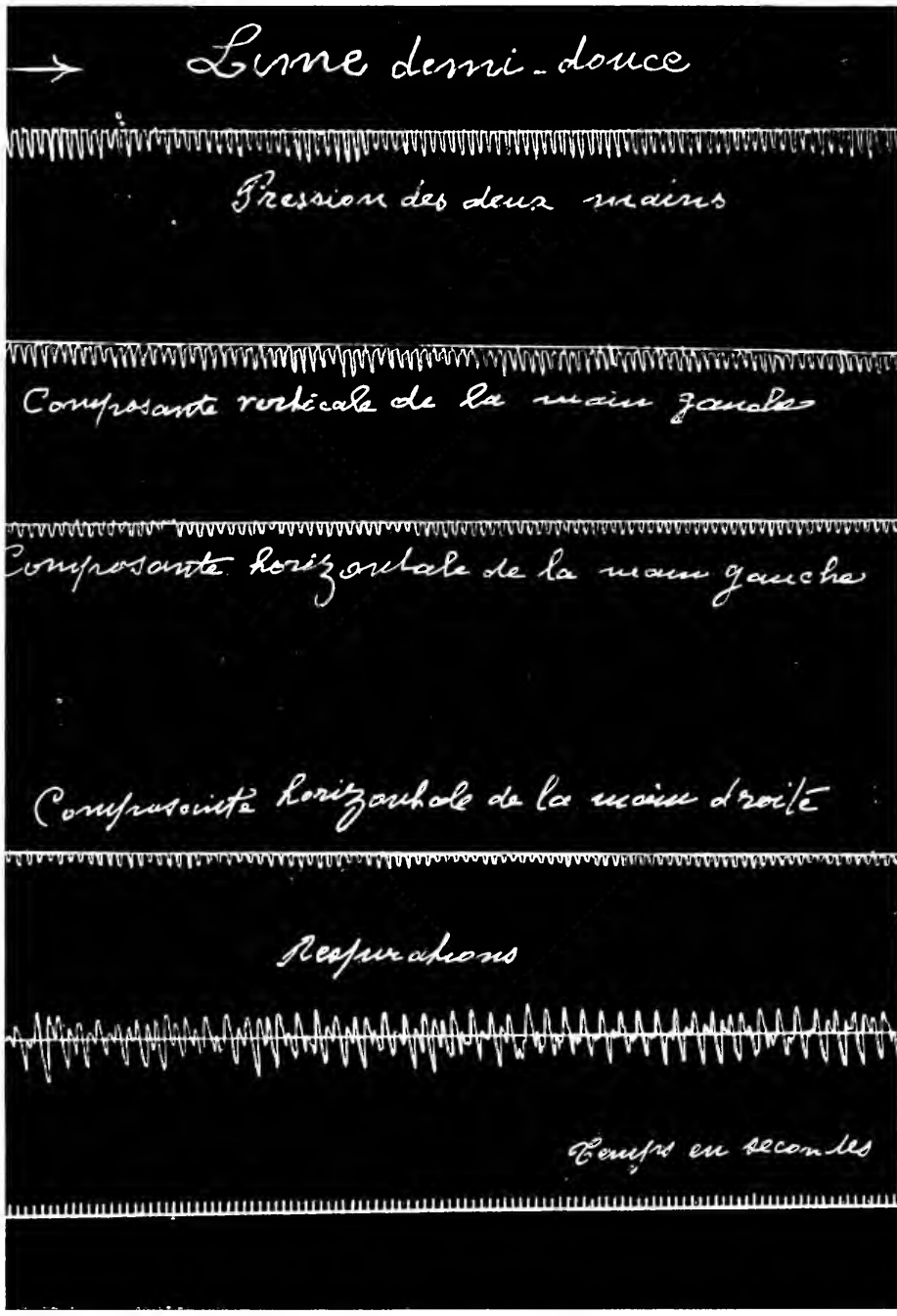

FIG. 13.- Records of physiological movements in the operation of filing by an experieneed worker. From above downward the successive curves represent respectively: The vertical pressure of the two hands; the vertical pressure of the left hand; the horizontal pressure of the left hand; the horizontal pressure of the right hand; the respiratory movements; the time in seconds. (From Amar, Organisation Physiologique du Trarail.) 


\section{Pince deni-douce}

\begin{tabular}{|c|}
\hline Sression matiale das dewa mains \\
\hline
\end{tabular}

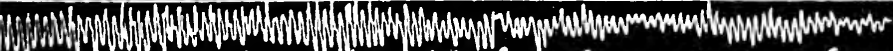

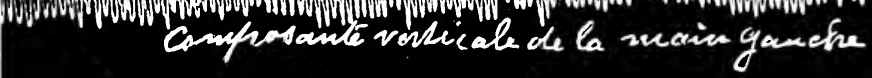

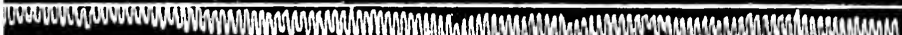
c

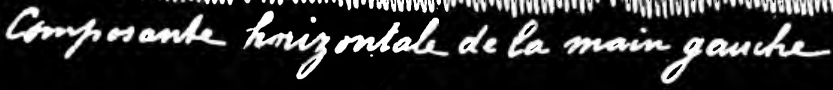

\section{composante tiong ontale de $b$ man droite}

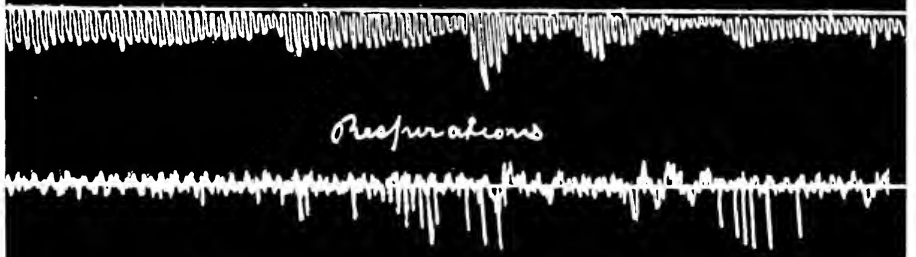
rempes en secondes

FIG. 14.-Records of physiological movements in the operation of filing by an inexperienced worker. From above downward the successive curves represent respectively: The vertical pressure of the two hands; the vertical pressure of the left hand; the horizontal pressure of the left hand; the horizontal pressure of the right hand; the respiratory movements; the time in seconds. (From Amar, Organisation Physiologique du Travail.) 
1 
and one hour is preferable. -If night work is necessitated it should be confined to men only, and the working night should not be longer than the working day. Exact records of the output of all individual workers should be kept, where the nature of the work makes it possible, and the effects on output of changes in the working conditions should be carefully observed. Constant watch should be made, with the help of exact tests if possible, for evidences of over-fatigue, and if they are found, the conditions of labor for the individual should be lightened. Overtime should be resorted to, if at all, only in occasional emergencies, and should be followed by at least an equal period of rest, taken from the following day's work. Six working days should be followed by one day of rest. Legal holidays should be strictly observed, and a half-holiday on a week day is advisable. Women can be advantageously employed for a large number and variety of the operations that do not demand great muscular strength, and they are especially efficient as inspectors; they should not be given night work. Any physical conditions of the shop, such as bad lighting, poor ventilation, and excessive heat, that conduce to fatigue, should be eliminated. Modern sanitary provisions for the worker's comfort and health should be maintained within the factory, and rest rooms and, so far as practicable, chairs 
should be provided for women. Safety devices against the hazards of work should be maintained. If good restaurants, adequate in size, do not exist near the factory, the company should provide dining rooms where food, planned according to the principles of modern scientific dietetics and well cooked, can be had at cost prices for such workers as do not live near the factory. The company should maintain at the factory a medical and nursing staff, and should attend to all cases of sickness or injury in which first aid is required. If comfortable housing for the workers is not available, the company should devise plans by which it may be had at reasonable prices. Employers should have decent regard for the welfare of their employees outside the factory, but should not impose their attentions too autocratically. Workers, once proved competent, should be retained, and every effort should be made to secure a low labor turnover. During the war emergency special efforts should be made to stimulate the patriotism of the workers, and they should be made to realize that they individually have an important part to play in the winning of the war and in helping to establish in the world the rule of right and justice. In so far as these conditions, formidable, I will allow, in number and difficulty of attainment but not impossible, can be established, industrial 
efficiency will be by so much achieved, and the ending of the war will be by so much hastened. It was only a few months ago that a clear-sighted Frenchman (53) wrote: "A nation finds itself to-day in danger of defeat, not because it does not know how to fight, but because it does not know how to manufacture."

The war will end, however, and industrial effort will still continue. The principles which I have here been presenting will, I trust, prove to be pertinent long after the war has ceased.

I cannot close this brief sketch without pointing out what seems to me a close parallelism in their historical development between medicine and industrialism. In both there is a conflict between the old and the new, between empiricism and tradition on the one side and science on the other. In medicine in recent decades science has been rapidly winning, and the chief single agency in this victory has been the experimental method, the method which more than all others characterizes modern science. Industrialism is not so far advanced in its evolution as is medicine; it is still lamentably under the control of empiricism and tradition; but science is making progress here. In this general industrial advance it is becoming increasingly clear that in all that pertains to the efficiency of the worker the physiological point of 
view is the most helpful point of view. In our analysis of the conditions of efficiency we always come ultimately to the underlying fact that the worker is a physiological mechanism and must be treated as such. Here is the proper scientific basis for the organization of industrial work. We already have the promising beginnings of a science of industrial physiology. What is needed now is a great extension of the method of experiment, partly in laboratories, but especially in factories, by which facts may be accumulated, principles may be established, and this new science may be rationally developed. In this direction I believe that industry has in America to-day an unparalleled opportunity for progress. 


\section{BIBLIOGRAPHY}

1. In the United States, the Public Health Service has been conducting, since July, 1917, an investigation of the conditions of labor in certain of the munition factories, for the purpose of discovering whether excessive fatigue is present, how it may be avoided, and how a continuous maximum production of war supplies may be secured. The work has been carried on with the active cooperation of the Divisional Committee on Industrial Fatigue under the Advisory Commission of the Council of National Defense. This Committee has now been constituted also the Sub-committee on Fatigue in Industrial Pursuits of the National Research Council. The membership of the Divisional Committee is as follows:

Thomas Darlington, Secretary Welfare Committee, American Iron and Steel Institute, Chairman.

Frederic S. Lee, Professor of Physiology, Columbia University; Chairman of the Sub-committee on Fatigue in Industrial Pursuits of the National Research Council; Consulting Physiologist, Public Health Service; Executive Secretary.

Robert E. Chaddock, Associate Professor of Statistics, Columbia University. 
Raymond Dodge, Professor of Psychology, Wesleyan University.

David L. Edsall, Professor of Clinical Medicine, Harvard Medical School.

P. Sargant Florence, Organizing Secretary of the Committee of the British Association for the Advancement of Science appointed to investigate Fatigue from the Economic Standpoint; recently Investigator of Industrial Fatigue under the British Health of Munition Workers Committee; Scientific Assistant (Supervising Field Investigator), Public Health Service.

Josephine Goldmark, Publication Secretary, National Consumers' League; Special Expert, Public Health Service. Ernest G. Martin, Professor of Physiology, Leland Stanford University; Scientific Assistant (Physiologist), Public Health Service; Captain Sanitary Corps, U.S. A.

A. H. Ryan, Professor of Physiology, Tufts Medical College; Scientific Assistant, Public Health Service.

J. W. Schereschewsky, Assistant Surgeon .General, in Charge of Division of Scientific Research, Public Health Service. Ernest L. Scott, Associate in Physiology, Columbia University; Captain, Sanitary Corps, U. S. A.

Of the many data which have been accumulated by the Public Health Service in the above investigation and are quoted in the present text few have yet appeared in print. They are here made public by the courtesy of the Service. Full reports of the investigation will ultimately be published by the Service. The Divisional Committee has published (1918) a pamphlet entitled "How Industrial Fatigue May be Reduced," which constitutes No. 1 of the Welfare Work Series issued by the Com- 
mittee on Labor under the Advisory Commission of the Council of National Defense.

2. In Great Britain, the Health of Munition Workers Committee, under the Ministry of Munitions, has conducted, since September, 1915, an investigation of the conditions of labor in munition factories. The following reports of this work have been published:

\section{Memorandum}

No.

1. Report on Sunday Labour. 1915.

2. Welfare Supervision. 1915.

3. Report on Industrial Canteens. 1915.

4. Employment of Women. 1916.

5. Hours of Work. 1916.

6. Canteen Construction and Equipment. 1916.

7. Industrial Fatigue and its Causes. 1916.

8. Special Industrial Diseases. 1916.

9. Ventilation and Lighting of Munition Factories and Workshops. 1916.

L 10. Sickness and Injury. 1916.

11. Investigation of Workers' Food and Suggestions as to Dietary. 1916.

12. Statistical Information Concerning Output in Relation to Hours of Work. 1916.

13. Juvenile Employment. 1916.

14. Washing Facilities and Baths. 1916.

15. The Effect of Industrial Conditions upon Eyesight. 1916.

16. Medical Certificates for Munition Workers. 1917.

17. Health and Welfare of Munition Workers Outside the Factory. 1917.

18. Further Statistical Information Concerning Output in Relation to Hours of Work, with Special Reference to the Influence of Sunday Labour. 1917. 
Memorandum

No.

19. Investigation of Workers' Food and Suggestions as to Dietary. Revised Edition. 1917.

L 20. Weekly Hours of Employment. 1917.

21. An Investigation of the Factors Concerned in the Causation of Industrial Accidents. 1918.

$\checkmark$ Interim Report. Industrial Efficiency and Fatigue. 1917.

Health of the Munition Worker. Handbook Prepared by the Health of Munition Workers Committee. 1917.

Some of these reports have been reprinted by the U. S. Department of Labor as follows:

Memorandum

Nos.

$1,5,7,8,9,10,12$ and 15 in Bulletin of the United States

Bureau of Labor Statistics, No. 221, entitled "Hours, Fatigue and Health in British Munition Factories." 1917.

2, 3, 6, 11 and 14 in Bulletin of the United States Bureau of Labor Statistics, No. 222, entitled "Welfare Work in British Munition Factories." 1917.

4 and 13 in Bulletin of the United States Bureau of Labor Statistics, No. 223, entitled "The Employment of Women and Juveniles in Great Britain during the War." 1917.

A summary of the reports has been published as follows:

Walter: Munition Workers in England and France. New York, Russell Sage Foundation, 1917.

3. Münsterberg: Psychology and Industrial Efficiency. Boston, 1913. 
4. Hollingworth: Vocational Psychology, its Problems and Methods. New York, 1916.

5. Lovett and Martin: The Spring Balance Muscle Test. American Journal of Orthopedic Surgery, XIV, 415, 1916. See also Martin and Rich: American Journal of Physiology, XLVII, 1918; Mosher and Martin: Journal of the American Medical Association, LXX, 1918.

6. Florence: Use of Factory Statistics in the Investigation of Industrial Fatigue. A Manual for Field Research. Columbia University. New York, 1918.

British Association for the Advancement of Science: The Question of Fatigue from the Economic Standpoint. Interim Report of the Committee, consisting of Professor J. H. Muirhead (Chairman), Miss' B. L. Hutchins (Secretary), Mr. P. Sargant Florence (Organizing Secretary), et al. Proceedings of the British Association for the Advancement of Science, p. 283, 1915. Second Interim Report, Do., p. 251, 1916.

7. Ryan: The Quantitative Measurement of General Fatigue. Proceedings of the American Physiological Society, American Journal of Physiology, XLV, 537, 1918.

8. Kent: Interim Report on an Investigation of Industrial Fatigue by Physiological Methods. London, 1915. Second Interim Report, Do. London, 1916.

9. The literature of fatigue is very voluminous. For brief reviews of the physiological aspect of the subject the following papers may be consulted:

Lee: Fatigue. Journal of the American Medical Association, XLVI, 1491, 1906. Do. Harvey Lectures, 1905-06. Philadelphia, 1906.

Lee: The Nature of Fatigue. Popular Science Monthly, LXXVI, 182, 1910.

Lee and Aronovitch: Does a Fatigue Toxin Exist? Proceedings of the Society for Experimental Biology and Medicine, XIV, 153, 1917. 
The industrial aspect of fatigue is presented comprehensively in:

Goldmark: Fatigue and Efficiency. New York, 1912.

10. Gilbreth: Motion Study. New York, 1911.

11. Gilbreth and Gilbreth: Fatigue Study. New York, 1916.

12. Lee: The Effects of Temperature and Humidity on Fatigue. American Journal of Public Health, II, 863, 1912.

Winslow, Kimball, Lee, Miller, Phelps, Thorndike and Palmer: Some Results of the First Year's Work of the New York State Commission on Ventilation. American Journal of Public Health, V, 85, 1915. The full report of the Commission has not yet been published.

13. Lee and Scott: The Action of Temperature and Humidity on the Working Power of Muscles and the Sugar of the Blood. American Journal of Physiology, XL, 486, 1916.

14. Lee: Fresh Air. Popular Science Monthly, LXXXIV, 313, 1914.

15. Taylor: The Principles of Scientific Management. New York and London, 1911.

16. Lee: Is the Eight-Hour Working-Day Rational? Science, XLIV, 727, 1916.

17. Mather: The Forty-eight Hours' Week; a Year's Experience and Its Results at the Salford Iron Works, Manchester. Manchester, 1894.

18. Fromont: Une Expérience Industrielle de Réduction de la Journée de Travail. Instituts Solvay. Brussels and Leipzig, 1906.

19. Abbe: Die Volkswirtshaftliche Bedeutung der Verkürzung des Industriellen Arbeitstages. Gesammelte Abhandlungen, III, 203. Jena, 1906.

20. Fitch: Hours and Output; Some War-time Testimony in Favor of a Short Work-day. The Survey, XXXVIII, 138, 1917.

21. Health of Munition Workers Committee: Further Statistical Information Concerning Output in Relation to 
Hours of Work, with Special Reference to the Influence of Sunday Labour. Memorandum No. 18. London, 1917. Health of the Munition Worker. London, 1918.

22. James: The Energies of Men. New York, 1908.

23. Martin, Withington and Putnam: Variations in the Sensory Threshold for Faradic Stimulation for Normal Human Subjects. 3. The Influence of General Fatigue. American Journal of Physiology, XXXIV, 97, 1914.

24. Kent: The Monday Effect in Industry. Proceedings of the Physiological Society, Journal of Physiology, L, lv, 1915-16.

25. Ayres: Music's Effect on Six-day Cyclists. Bicycling World and Motorcycle Review. 1911.

26. Mosso: Fatigue. New York, 1904.

27. Hayhurst: Report of the Illinois Commission on Occupational Diseases, 49, 1911.

28. Alexander: Cost of Labor Turnover. Proceedings of the Employment Managers' Conference, Philadelphia, Pa., April 2 and 3, 1917. Bulletin of the United States Bureau of Labor Statistics, No. 227. Washington, 1917.

29. Andrews: Economic Effects of the War upon Women and Children in Great Britain. New York, 1918.

30. Thompson: The Mental Traits of Sex. Chicago, 1903.

31. Weinberg: Krankheit und Soziale Lage. Der Einfluss der Sozialen Lage auf Krankheit und Sterblichkeit der Frau. Berlin, 1913.

32. Layet: Le Travail des Enfants et des Femmes dans l'Industrie. Encyclopédie d'Hygiène et de Médecine Publique, VI. Paris, 1894.

33. Warren and Sydenstricker: Health Insurance; its Relation to the Public Health. Public Health Bulletin, No. 76. Washington, 1916.

34. Hollingworth: Functional Periodicity. An Experimental Study of the Mental and Motor Abilities of Women during Menstruation. New York, 1914.

35. Simpson and Galbraith: Observations on the Normal 
Temperature of the Monkey and its Diurnal Variation, and on the Effect of Changes in the Daily Routine on this Variation. Transactions of the Royal Society of Edinburgh, XLV, $65,1905$.

36. Linhard: Report of the Danish Expedition to the Northeast Coast of Greenland, 1906-8, XLIV. Copenhagen, 1910.

37. Benedict: Studies in Body Temperature. 1. Influence of the Inversion of the Daily Routine; the Temperature of Night-workers. American Journal of Physiology, XI, $145,1904$.

38. Health of Munition Workers Committee: Industrial Efficiency and Fatigue. Interim Report. London, 1917.

39. U. S. Department of Labor: Accidents and Accident Prevention. Report on Conditions of Employment in the Iron and Steel Industry in the United States, IV. Senate Document No. 110, 62d Congress. Washington, 1913.

40. New York State Factory Investigating Commission: Night-work of Women in Factories. Second Report of Commission, I, 1913.

41. Brandeis and Goldmark: The Case Against Nightwork for Women. National Consumers' League. New York, 1918.

42. Bogardus: The Relation of Fatigue to Industrial Accidents. American Journal of Sociology, XVII, 1912.

43. Departmental Committee on Lighting in Factories and Workshops. First Report, I. London, 1915.

44. Kober and Hanson: Diseases of Occupation and Vocational Hygiene. Philadelphia, 1916.

Thompson: The Occupational Diseases: Their Causation, Symptoms, Treatment and Prevention. New York, 1914.

45. Abbott and Gildersleeve: The Influence of Muscular Fatigue and of Alcohol upon Certain of the Normal Defences. University of Pennsylvania Medical Bulletin, XXIII, 169, 1910.

46. Jones: The Administration of Industrial Enterprises. 
New York and London, 1917. See also Tolman: Social Engineering. New York, 1909.

47. Lusk: The Fundamental Basis of Nutrition. New Haven, 1914.

48. Stern and Spitz: Food for the Worker. Boston, 1917.

49. Rose: Feeding the Family. New York, 1917.

50. Of the voluminous literature of Scientific Management, the reader may profitably consult the following books:

Taylor: The Principles of Scientific Management. New York and London, 1911.

Gantt: Work, Wages and Profits. New York, 1913.

Emerson: Efficiency as a Basis for Operation and Wages. New York, 1914.

Thompson: Scientific Management, A Collection of the More Significant Articles Describing the Taylor System of Management. Cambridge, 1914.

Drury: Scientific Management, A History and Criticism. Columbia University. New York, 1915.

Hoxie: Scientific Management and Labor. New York and London, 1916.

51. Imbert and Méstre: Travaux Originaux des Inspecteurs. Recherches sur la Manœuvre du Cabrouet et la Fatigue qui en Résulte. Bulletin de l'Inspection du Travail, XIII and XIV, 374, 1905.

Imbert: Les Méthodes du Laboratoire Appliquées a l'Etude Directe et Pratique des Questions Ouvrières. Revue Générale des Sciences Pures et Appliquées, XXII, 478, 1911. 52. Amar: Organisation Physiologique du Travail. Paris (Dunod \& Pinat), 1916.

53. Hamp: La France Pays Ouvrier. Paris, 1916.

54. National Industrial Conference Board: Hours of Work as Related to Output and Health of Workers, Cotton Manufacturing. Research Report Number 4. Do., Boot and Shoe Industry, Research Report Number 7, Boston, 1918. 
.

a 


\section{INDEX}

Abbott and Gildersleeve, 80

Accidents, 73; and fatigue, 74, 78; hourly distribution of, 74; and illumination, 76; and inexperience, 74; and night work, 68,77

Acidosis, 16

Age of workers, 47

Alexander, 49, 50

Amar, 97

Bogardus, 73, 74

Ca' canny, 39

Capacity and output, 39

Chaney, 68

Day work compared with night work, 61

Efficiency, conditions of, 4

Efficiency engineering, 90

Eight-hour day, 27, 31, 36

Emerson, 93

Employers, duties of, 42

Engis Chemical Works, 33

Epstean, 59

Fatigue, and accidents, 74, 78; and age, 48; and composition of urine, 16; and hearing, 15; and heat and humidity, 21; and illumination, 21; and infection, 80; and luncheon, 25; and mental influences, 44; and monotonous work, 18 ; of muscle, 13, 24; in muscular work, 16; and music, 
45; and output, 10; primary and secondary sources of, 19 ; and rest, 24, 45; and sight, 15, 46; and strength, 14; tests for, 14; and ventilation, 21; weekly, 43

Fatigue substances, 24

Filing, physiological analysis of, 97

Food, 22, 84

Gantt, 93

Gilbreth, 19, 96

Greenwood, 67

Hamp, 103

Hastings, 16

Hayhurst, 47

Health of Munition Workers Committee, 34, 45, 47, 67, 71, 88 Hearing and fatigue, 15

Heat and fatigue, 21

Hollingworth, 7, 58

Human machine, 2, 29, 104

Humidity and fatigue, 21

Illumination, and accidents, 76; and fatigue, 21

Imbert and Mestre, 96

Industrial medicine, 79

Industrial operations, repetitive, 10 ; varicty of, 5

Industry, and medicine, 103; and physiology, 3, 4, 104; and war, 3

Infection and fatigue, 80

James, 39

Jones, 81

Kent, 15, 43, 46

Labor turnover, 49

Lee, 21 
Lovett and Martin, 8, 14

Luncheon and fatigue, 25

Machinery, 1

Martin, 8, 14, 43

Medicine, industrial, 79; and industrialism, 103

Menstruation, 58

Mental influences and fatigue, 44

Monday effect, 43

Monotonous work and fatigue, 18

Mosso, 46

Münsterberg, 6

Muscle, fatigue of, 13, 24

Muscular work and fatigue, 16

Music and fatigue, 45

National Industrial Conference Board, 38

Night work, 61 ; and accidents, 68,77 ; alternation with day work, 71; efficiency of, 67 ; and health, 68 ; output of, 64 ; and sleep, 70

Opsonic index and fatigue, 80

Output, and capacity, 39; curves of, 12, 17, 65; of day work,

11 ; and fatigue, 10; limiting of, 39; of night work, 66; and scientific management, 92; stereotyping of, 40

Overtime, 46

\section{Paget, 79}

Physiological organization of work, 96

Physiology and industry, 3, 4, 104

Piece-rate, effect of cutting, 41

"Practical " point of view, 3

Practice effect, 14, 44

Public Health Service, 8, 10, 15, 16, 21, 27, 40, 50, 58, 64, 72,87 
Rate setting, 42

Repetitive operations, 10

Rest and fatigue, 24, 45

Resting periods, 24

Rose, 85

Ryan, 15

Salford Iron Works, 32

Scientific management, 90

Scott, 21

Secondary sources of fatigue, 19

Shoe manufacture, 33

Sight and fatigue, 15, 46

Sleep and night work, 70

Soldiering, 39

Spring balance test, 8,14

Strength, and fatigue, 14; standard, 8

Sunday work, 47

Taylor, 25, 90, 92, 93

Taylorism, 90

Temperature of body, 62

Tests, for fatigue, 14; for vocational fitness, 6

Thompson, 54

Trench-digging, 27

Treppe, 13

Vascular skin reaction test, 15

Ventilation and fatigue, 21

Vernon, 28, 34, 68

War and industry, 3

Welfare work, 81

Women, absences of, from work, 58 ; differences between men and, 54; health of, 57; increase in employment of, 53 ; industrial efficiency of, 53; and night work, 70, 72 


\section{INDEX}

Workers, age of, 47; duties of, 4, 42; qualifications of, 5

Working day, effect of shortening, 31; length of, 29

Working power, maintenance of, 43

Zeiss Optical Works, 33 


THIS BOOK IS DUE ON THE IAST DATE STAMPED BELOW

AN INITIAL FINE OF 25 CENTS WILL BE ASSESSED FOR FAILURE TO RETURN THIS BOOK ON THE DATE DUE. THE PENALTY WILL INCF

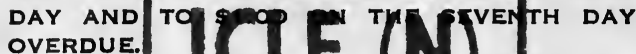

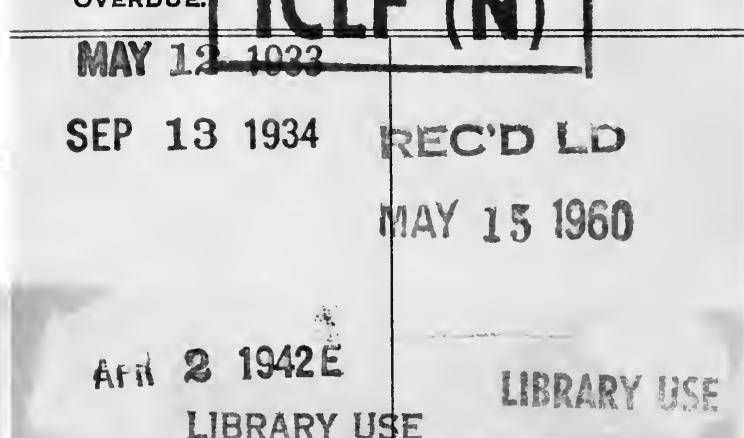
LIBRARY USE

LRRARY USE MAY 261953 MAY 8 ' 65 2Dec'55EO $J A N$
.5 है 31956 UAB 8 '65-3PM 960. LIBRARY USE MAY 151950 FEB 13 2006AUG 161999 


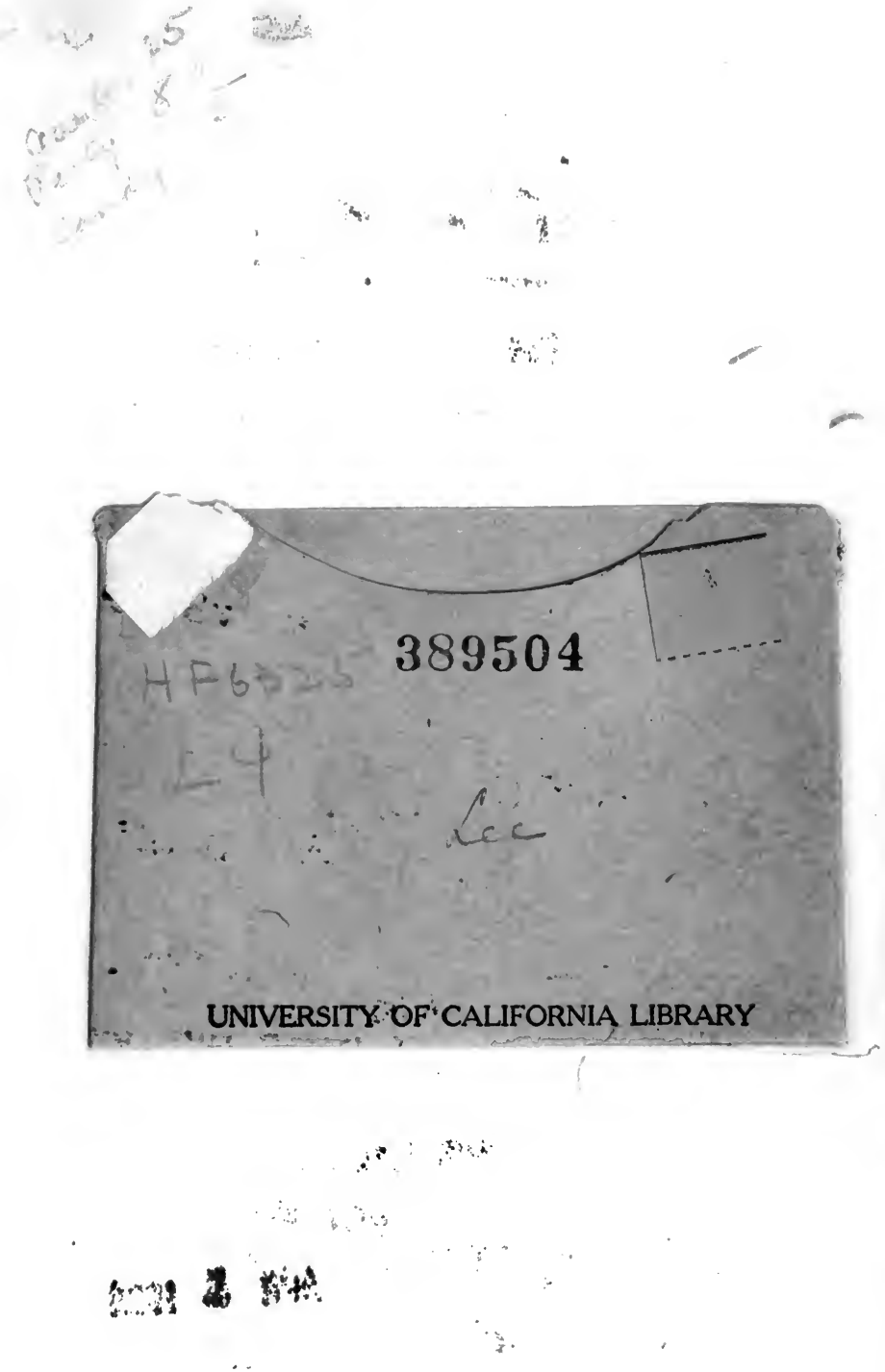


